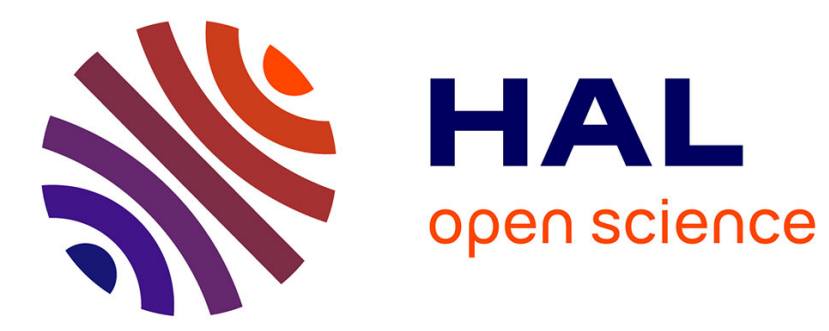

\title{
Optical fibers by butyl methacrylate reactive extrusion
} Romuald Berthet, Yvan Chalamet, Mohamed Taha, Amar Zerroukhi

\section{To cite this version:}

Romuald Berthet, Yvan Chalamet, Mohamed Taha, Amar Zerroukhi. Optical fibers by butyl methacrylate reactive extrusion. Macromolecular Materials and Engineering, 2006, 29 (6), pp.720 - 731. 10.1002/mame.200500428 . ujm-00086025

\section{HAL Id: ujm-00086025 \\ https://hal-ujm.archives-ouvertes.fr/ujm-00086025}

Submitted on 17 Jul 2006

HAL is a multi-disciplinary open access archive for the deposit and dissemination of scientific research documents, whether they are published or not. The documents may come from teaching and research institutions in France or abroad, or from public or private research centers.
L'archive ouverte pluridisciplinaire HAL, est destinée au dépôt et à la diffusion de documents scientifiques de niveau recherche, publiés ou non, émanant des établissements d'enseignement et de recherche français ou étrangers, des laboratoires publics ou privés. 


\title{
Optical fibers by butyl methacrylate reactive extrusion
}

\author{
Berthet Romuald, Chalamet Yvan, Taha Mohamed*, Zerroukhi Amar \\ Université jean Monnet \\ Faculté des sciences
}

Laboratoire de Rhéologie des Matières Plastiques, UMR CNRS 5156

23, Rue du docteur Michelon

42023 Saint Etienne Cédex 02, France

mtaha@univ-st-etienne.fr

\begin{abstract}
A process for a poly(butyl methacrylate) optical fibers production by reactive extrusion was developed. The reactive system was adapted to the reduced reaction time in the extruder combining concepts based on the free volume theory and a kinetic model for mass polymerization a butyl methacrylate.

A kinetic model was proposed and the reaction evolution was simulated at different temperature and initiator concentration. This allowed the choice of reaction conditions in adequation with reactive extrusion technical limitations.

Reactive extrusion experiments were carried out in a twin-screw extruder and the effect of the different kinetic and process conditions on the reaction were analyzed in relation with the
\end{abstract}


residence time distribution measured by an UV fluorescence method. Some optical properties of poly(butyl methacrylate) fibres were reported.

Keywords : reactive extrusion, radical polymerization, kinetics, polymer optical fibbers, polymethacrylate.

\section{Introduction}

Twin screw extruders are playing an increasing role in chemical polymer modification or polymerization. ${ }^{[1]}$ One early published example of reactive extrusion was the bulk polymerization of caprolactam ${ }^{[2]}$ in extruder. Since this study, the use of extruder was spread to the polymerization of acetal, ${ }^{[1]}$ styrene, ${ }^{[3]}$ and lactam $^{[4]}$ but also to increase the molar mass of polyamide ${ }^{[5]}$, the rheology control of polyolefin's ${ }^{[6]}$ and prepolymers synthesis ${ }^{[7]}$. This intense activity in the field of reactive extrusion is explained by the different advantages offered by the use of the twin-screw extruders as continuous chemical reactors. The important mixing capacity, even with high viscosity polymers, combined to the flexibility in the screw profile, favors thermal exchanges, and allows the control of the chemical reactions during extrusion. For the mass radical polymerization an important increase of the reaction rate can result from the trommsdorff or gel effect caused by diffusion control of termination reaction. The thermal exchange in the twin-screw extruder is supposed to stabilize the temperature. 
The material synthesised here is destined to optical application: the objective is to develop a one-step process for the elaboration of a polymer material having weak optical absorption.

In this work, the study of optical properties allowed first the choice of the monomer to use for fibres preparation. Than a kinetic modelling leaded to a correct choice of reaction conditions and to adapt the reactive system to the process. Than the reactive extrusion process parameters were analyzed and optimised.

\section{Experimental}

\section{Materials}

The butyl methacrylate (BMA, Acros) monomer was distilled and mixed with a combination of three initiators, 2,2'-Azobis(2,4-dimethylvaleronitrile) (AVN, vazo 52, Du Pont), Azobis isobutyronitrile (AIBN, Acros), 1,1'-Azobis 1-cyclohexanecarbonitrile (ACN, vazo 88, Du Pont). These initiators are characterized by a half-life time of $10 \mathrm{~h}$ at respectively $52^{\circ} \mathrm{C}, 64^{\circ} \mathrm{C}$ and $88^{\circ} \mathrm{C}$.

\section{Kinetic measurement}

Kinetic constant values and conversion were determined from differential calorimetry measurements with a SETARAM DSC 141 under nitrogen. 10-15 mg samples were used. Four metals (Hg-In-Pb-Zn) were used to calibrate the temperature and enthalpy values. 


\section{Molar mass measurements}

Size exclusion chromatography (SEC) of poly (butyl methacrylate) (PBMA) were performed using a Waters 515 device equipped with a U6K injector, and a double detector (UV at 254 nm and differential refractometer R410). Columns of Waters HR 1, HR 3 and HR 4 with a separation performance ranging from $10^{2}$ to $6 \cdot 10^{5} \mathrm{~g} \cdot \mathrm{mol}^{-1}$ in weight average molar mass of polystyrene, were used. Tetrahydrofuran (THF) was used as a solvent at a $1 \mathrm{ml} / \mathrm{min}$ flow rate. A calibration curve was established using PBMA standards.

\section{Extrusion}

A CLEXTRAL BC 21 modular fully intermeshing corotating twin screw extruder was used. The screw diameter was $25 \mathrm{~mm}$, the total barrel length was $900 \mathrm{~mm}$, and the centerline distance was $21 \mathrm{~mm}$. The obtained polymers were extruded through a cylindrical die. The extruder screw profile is given in figure 1.

Reactants (monomer and initiators) were pumped into the feeder. Samples were collected when the extruder reached a steady state and were frozen in liquid nitrogen to stop the reaction.

The conversion of extruded samples is obtained from SEC measurements. Tri(ethylene glycol)dimethacrylate was used as internal standard for the measurement of BMA concentration.

Residence Time distribution Measurements 
An UV fluorescence technique ${ }^{[8]}$ was used for residence time distribution (RTD) measurements on the extruder die and along the screw. Typically $0.1 \mathrm{~g}$ of anthracene was used as UV detectable tracer.

Generally the RTD may be described quantitatively with the function, E(t). This function represents the exit age distribution of the polymer from the extruder.

$$
E(t)=\frac{C_{i}}{\sum_{0}^{\infty} C_{i} \Delta t}
$$

$\mathrm{C}_{\mathrm{i}}$ is the concentration of the tracer in each sample, and $\Delta \mathrm{t}$ the time between two successive sampling.

To compare different distributions, the first moment, also called mean residence time, $\overline{\mathrm{t}}_{\mathrm{m}}$, and the variance $\sigma^{2}$ are used:

$$
\begin{aligned}
& \overline{\mathrm{t}}_{\mathrm{m}}=\sum_{0}^{\infty} \mathrm{tE}(\mathrm{t}) \Delta \mathrm{t} \\
& \sigma^{2}=\frac{\sum_{0}^{\infty} t_{i}^{2} C_{i} \Delta t_{i}}{\sum_{0}^{\infty} C_{i} \Delta t_{i}}-\overline{\mathrm{t}}_{m}^{2}
\end{aligned}
$$

The $F(t)$ function, or cumulative distribution is also obtained by integrating the $E(t)$ function : 


$$
F(t)=\frac{\sum_{0}^{t} C_{i} \Delta t}{\sum_{0}^{\infty} C_{i} \Delta t}
$$

It is convenient to normalize the data to the mean residence time.

$$
\begin{aligned}
& \theta=\frac{t}{\frac{\mathrm{t}_{\mathrm{m}}}{2}} \\
& \mathrm{E}(\theta)=\overline{\mathrm{t}} \mathrm{E}(\mathrm{t}) \\
& \mathrm{F}(\theta)=\mathrm{F}(\mathrm{t})
\end{aligned}
$$

\section{Dispersion}

The axial dispersion can be characterized by the dimensionless Peclet number. This number is the ratio between a convection term, represented by the average axial velocity $U$, the length of the reactor $\mathrm{L}$, and a dispersion coefficient $\mathrm{D}$ :

$$
P e=\frac{\mathrm{UL}}{\mathrm{D}}
$$

The Peclet number tends to be infinite when the reactor behaves as a plug flow reactor. Inversely it tends to zero when the reactor behavior approaches a perfectly mixed flow. The Pe number is related to the experimental condition by the following equation:

$$
\sigma_{\theta}^{2}=\frac{2}{\mathrm{Pe}}-\frac{2}{\mathrm{Pe}^{2}}[1-\exp (-P e)]
$$


Synthesis of fibres for optical characterisation:

The BMA and 0.1mol.\% AIBN initiator were poured into an hexafluoropropylenetetrafluoroethylene copolymer (FEP) tube under nitrogen atmosphere than the tube ends were sealed. The tube was placed in an oven where the temperature increased from $20^{\circ} \mathrm{C}$ to $80^{\circ} \mathrm{C}$ with a ramp of $1^{\circ} \mathrm{C} / \mathrm{min}$. than the temperature was kept constant for 24 hours to achieve the polymerization.

\section{Optical properties measurements}

The optical transmission of samples in the field of UV / Vis was determined from a JASCO $7800 \mathrm{UV}$ / Vis spectrometer. The transmissions and attenuations were measured on $50 \mathrm{~cm}$ length samples.

\section{Results and Discussion}

Choice of the monomer for optical fibres elaboration:

A material for optical application, notably for information transport, should minimise the optical losses.

Generally optical losses in a material have two origins: ${ }^{[9]}$

- The intrinsic losses that depend on the structure of the material and the chemical composition: they principally result of the absorption due to the harmonic vibrations of the 
chemical bonds and the electronic absorption. For the $\mathrm{CH}$ bonds, the first harmonics are between 540 and $3400 \mathrm{~nm}$. Electronic absorptions are essentially due to the double bonds These losses are a function of the wavelength $\lambda$ and vary with the composition and the morphology of the material.

- The extrinsic loss is due to fabrication process: principally contaminating dust. It can be decreased to a negligible amount.

Poly(butylmethacrylate) and poly (2-hydroxyethylmethacrylate) fibres were prepared and analyzed. The measured attenuations are reported in Figure 2.

As expected, absorptions due to the harmonics of the $\mathrm{C}-\mathrm{H}$ bonds of the polymers are obtained towards $750 \mathrm{~nm}$.

Comparing the two polymers absorptions, one notes that poly( butyl methacrylate) leads to lower attenuation than ploy(2- hydroxy ethyl methacrylate ) in a large wavelength range. This is in favor of the choice of poly( butyl methacrylate ) for the rest of this study.

The effect of residual BMA and AIBN in PBMA fibber absorption is illustrated in Figure 3. Even for relatively low concentrations of residual monomer, attenuation between $240 \mathrm{~nm}$ and $400 \mathrm{~nm}$ increase is perceptible. These absorptions are due to $\mathrm{c}=\mathrm{c}$ double bond $(240-280 \mathrm{~nm})$ and the carbonyl function conjugated to the double bond $(300-320 \mathrm{~nm})^{[10]}$. 
For this reasons and others like the possibility of properties ulterior evolution of the issued material properties due to polymerization of residual monomer or its evaporation, a maximum conversion should be obtained at the extruder die.

The aim of the next part is to predetermine the reaction conditions that should be used in reactive extrusion in order to obtain a complete conversion at the extruder exit.

Fitting the reaction to twin-screw extrusion process

Fitting the reaction to the extrusion process implies taking into consideration technical considerations and others related to the chemical reactions. These limitations can be considered using a reactive extrusion diagram ${ }^{[7]}$. In the present study the reaction kinetic is expected to define the kinetic conditions susceptible to lead to the expected conversion at he extruder die.

\section{Polymerization Kinetic Study}

\section{Kinetic Model}

The free radical polymerization rate of BMA is given in equation 10. :

$$
R_{p}=-\frac{d[M]}{d t}=k_{p} \sqrt{\frac{f k_{d}[I]}{k_{t}}}[M]
$$

Where $k_{d}, k_{p}, k_{t}$ are Initiator decomposition, propagation and termination rate constants 
The optimization of polymerization requires a description of the reaction evolution over the entire range of conversion. For this a model formulated by Panke ${ }^{[11]}$ based on the free volume theory, initially developed by Hamielec ${ }^{[12]}$ and modified by Buback. ${ }^{[13]}$ was used in this study. To take into account the gel effect, these authors consider that propagation and termination reactions are consecutive of translational diffusion, segmental diffusion and chemical reaction. This concept can be noted as:

$$
\frac{1}{\mathrm{k}_{\mathrm{p}}}=\frac{1}{\mathrm{k}_{\mathrm{pR}}}+\frac{1}{\mathrm{k}_{\mathrm{pD}}}
$$

Where $\mathrm{k}_{\mathrm{pR}}$ and $\mathrm{k}_{\mathrm{pD}}$ are respectively chemical and diffusion contribution to propagation.

According to Hamielec [12], $\mathrm{k}_{\mathrm{pD}}$ depends on the free volume of the system :

$$
\mathrm{k}_{\mathrm{pD}}=\mathrm{k}_{\mathrm{pD}}^{0} \exp \left[-\mathrm{v}_{\mathrm{p}}^{*}\left(\frac{1}{\mathrm{v}_{\mathrm{f}}}-\frac{1}{\mathrm{v}_{\mathrm{f}}^{0}}\right)\right]
$$

Where $\mathrm{v}_{\mathrm{p}}^{*}$ is an adjustable parameter, and $\mathrm{v}_{\mathrm{f}}$ and $\mathrm{v}_{\mathrm{f}}^{0}$ respectively the free volume of the system during the reaction and at initial time.

The $\mathrm{k}_{\mathrm{pR}}$ constant can be calculated at low conversion where $\mathrm{k}_{\mathrm{p}}=\mathrm{k}_{\mathrm{p}}^{0}, \mathrm{k}_{\mathrm{pR}}=\mathrm{k}_{\mathrm{pR}}^{0}$ and $\mathrm{k}_{\mathrm{pD}}=\mathrm{k}_{\mathrm{pD}}^{0}$. So equation (12) becomes: 


$$
\mathrm{k}_{\mathrm{p}}=\frac{1}{\frac{1}{\mathrm{k}_{\mathrm{p}}^{0}}-\frac{1}{\mathrm{k}_{\mathrm{pD}}^{0}}+\frac{\exp \left[\mathrm{v}_{\mathrm{p}}^{*}\left(\frac{1}{\mathrm{v}_{\mathrm{f}}}-\frac{1}{\mathrm{v}_{\mathrm{f}}^{0}}\right)\right]}{\mathrm{k}_{\mathrm{pD}}^{0}}}
$$

A similar treatment is applied for termination constant $\mathrm{k}_{\mathrm{t}}$ :

$$
\frac{1}{\mathrm{k}_{\mathrm{t}}}=\frac{1}{\mathrm{k}_{\mathrm{tR}}}+\frac{1}{\mathrm{k}_{\mathrm{tD}}}
$$

The chemical termination constant, $\mathrm{k}_{\mathrm{tR}}$, is higher than diffusion constant. So the $1 / \mathrm{k}_{\mathrm{tR}}$ in equation (14), can be neglected.

The diffusion constant, $\mathrm{k}_{\mathrm{tD}}$, can be decomposed in a translational and a segmental diffusion term:

$$
\frac{1}{\mathrm{k}_{\mathrm{tD}}}=\frac{1}{\mathrm{k}_{\mathrm{TD}}}+\frac{1}{\mathrm{k}_{\mathrm{SD}}}
$$

With $\mathrm{k}_{\mathrm{TD}}$ and $\mathrm{k}_{\mathrm{SD}}$ respectively translational and segmental diffusion constant.

The translational diffusion depends on the free volume and on the molar mass of macroradical and also of the dead polymer

$$
\mathrm{k}_{\mathrm{TD}}=\frac{\mathrm{k}_{\mathrm{TD}}^{\prime} \exp \left[-\mathrm{v}_{\mathrm{t}}^{*}\left(\frac{1}{\mathrm{v}_{\mathrm{f}}}-\frac{1}{\mathrm{v}_{\mathrm{f}}^{0}}\right)\right]}{\left(\overline{\mathrm{M}_{\mathrm{w}}} \overline{\overline{\mathrm{M}_{\mathrm{w}}}}\right)^{\mathrm{n}}}
$$


Where $\mathrm{k}_{\mathrm{TD}}^{\prime}, \mathrm{v}_{\mathrm{t}}^{*}$ and $\mathrm{n}$ are adjustable parameters, $\overline{\mathrm{M}_{\mathrm{w}}}$ is the macroradicals weight average molar mass and $\overline{\overline{\mathrm{M}_{\mathrm{w}}}}$ is the cumulative weight average molar mass of the dead polymer.

But, for high degrees of conversion, the termination process is also controlled by so called "reaction diffusion". This reaction is in parallel with translational and segmental diffusion. The equation (14) becomes :

$$
\mathrm{k}_{\mathrm{t}}=\frac{1}{\frac{1}{\mathrm{k}_{\mathrm{tD}}}+\frac{1}{\mathrm{k}_{\mathrm{SD}}}}+\mathrm{k}_{\mathrm{RD}}
$$

With

$$
\mathrm{k}_{\mathrm{RD}}=\mathrm{C}_{\mathrm{RD}} \mathrm{k}_{\mathrm{p}}[\mathrm{M}]
$$

And

$$
\frac{1}{\mathrm{k}_{\mathrm{SD}}}=\frac{1}{\mathrm{k}_{\mathrm{t}}^{0}-\mathrm{C}_{\mathrm{RD}} \mathrm{k}_{\mathrm{p}}^{0}[\mathrm{M}]^{0}}-\frac{\left(\overline{\mathrm{M}_{\mathrm{w}}^{0}}\right)^{2 \mathrm{n}}}{\mathrm{k}_{\mathrm{TD}}^{\prime}}
$$

Where $[\mathrm{M}]^{0}$ is the initial monomer concentration.

And finally we have :

$$
\mathrm{k}_{\mathrm{t}}=\left[\frac{1}{\mathrm{k}_{\mathrm{t}}^{0}-\mathrm{C}_{\mathrm{RD}} \mathrm{k}_{\mathrm{p}}^{0}[\mathrm{M}]^{0}}-\frac{\left(\overline{\mathrm{M}_{\mathrm{w}}^{0}}\right)^{2 \mathrm{n}}}{\mathrm{k}_{\mathrm{TD}}^{\prime}}+\frac{\left(\overline{\mathrm{M}_{\mathrm{w}}} \overline{\overline{\mathrm{M}_{\mathrm{w}}}}\right)^{\mathrm{n}} \exp \left[\mathrm{v}_{\mathrm{t}}^{*}\left(\frac{1}{\mathrm{v}_{\mathrm{f}}}-\frac{1}{\mathrm{v}_{\mathrm{f}}^{0}}\right)\right]}{\mathrm{k}_{\mathrm{TD}}^{\prime}}\right]^{-1}+\mathrm{C}_{\mathrm{RD}} \mathrm{k}_{\mathrm{p}}[\mathrm{M}]
$$


So the rate expression is given by equation (21) through (23):

$$
\begin{aligned}
& \frac{\mathrm{dx}}{\mathrm{dt}}=\frac{\mathrm{k}_{\mathrm{p}}}{\sqrt{\mathrm{k}_{\mathrm{t}}}} \sqrt{2 \mathrm{fk}_{\mathrm{d}}[\mathrm{I}]}(1-\mathrm{x}) \\
& \frac{\mathrm{d}[\mathrm{I}]}{\mathrm{dt}}=-[\mathrm{I}]\left[\mathrm{k}_{\mathrm{d}}+\frac{\varepsilon}{\rho_{\mathrm{M}} \mathrm{v}} \frac{\mathrm{dx}}{\mathrm{dt}}\right] \\
& \frac{\mathrm{d} \overline{\overline{\mathrm{M}_{\mathrm{w}}}}}{\mathrm{dt}}=\frac{\overline{\mathrm{M}_{\mathrm{w}}}-\overline{\overline{\mathrm{M}_{\mathrm{w}}}} \frac{\mathrm{dx}}{\mathrm{dt}}}{\mathrm{dt}}
\end{aligned}
$$

Where $\mathrm{x}$ is the monomer conversion, $\varepsilon$ the volumetric contraction coefficient, $\mathrm{v}$ the specific volume of the solution and $\rho_{M}$ the monomer density.

The different constants used in this study are listed in table 1.

Table 1. Constants used for the calculation

\begin{tabular}{ll}
\hline Constants & Reference \\
\hline $\mathrm{k}_{\mathrm{p}}^{0}=1.32 . \times 10^{6} \cdot \exp (-2320 / \mathrm{T})\left(\mathrm{L} \cdot \mathrm{mol}^{-1} \cdot \mathrm{s}^{-1}\right)^{\mathrm{a})}$ & this work \\
$\mathrm{k}_{\mathrm{t}}^{0}=1.35 \times 10^{9} \cdot \exp (-1395 / \mathrm{T})\left(\mathrm{L} \cdot \mathrm{mol}^{-1} \cdot \mathrm{s}^{-1}\right)^{\mathrm{a})}$ & this work \\
$\mathrm{C}_{\mathrm{RD}}=\quad 1.25 \mathrm{~L} / \mathrm{mol}$ & 13 \\
$-\varepsilon \quad=\quad 0.14717+1.019 \times 10^{-3} \cdot \mathrm{T}+9.9 \times 10^{-7} \cdot \mathrm{T}^{2 \text { a) c) }}$ & this work \\
$\rho_{\mathrm{M}}=\quad 0.91162-9.0 \times 10^{-4} \cdot \mathrm{T}^{\mathrm{a}) \mathrm{c}}$ & this work
\end{tabular}




$$
\begin{array}{lll}
\mathrm{T}_{\mathrm{gP}}=2^{\circ} \mathrm{C}^{\mathrm{b})} & \text { this work } \\
\Delta \alpha_{\mathrm{P}}=\quad 6.6 \times 10^{-4} \mathrm{~K}^{-1 \mathrm{a})} & \text { this work } \\
\mathrm{T}_{\mathrm{gM}}=\quad-135^{\circ} \mathrm{C}^{\mathrm{b})} & \text { this work } \\
\Delta \alpha_{\mathrm{M}}=\quad 10^{-3} \mathrm{~K}^{-1} & 13 \\
\mathrm{k}_{\mathrm{d}}=5.88 \times 10^{15} \mathrm{~s}^{-1} \exp (-16000 / \mathrm{T}) \text { d) for AIBN } & 9 \\
\mathrm{f}^{0}=6.37 \times 10^{-2} \cdot \exp (730 / \mathrm{T})^{\mathrm{d})} \text { for AIBN } & 9 \\
\mathrm{k}_{\mathrm{d}}=1.31 \times 10^{15} \mathrm{~s}^{-1} \exp (-14800 / \mathrm{T})^{\mathrm{d})} \text { for AVN } & \text { this work } \\
\mathrm{f}^{0}=1.34 \times 10^{-4} \cdot \exp (2600 / \mathrm{T})^{\mathrm{d})} \text { for AVN } & 9 \\
\mathrm{k}_{\mathrm{d}}=3.30 \times 10^{17} \mathrm{~s}^{-1} \exp (-18500 / \mathrm{T})^{\mathrm{d})} \text { for ACN } & \text { this work } \\
\mathrm{f}^{0}=1.20 \times 10^{-9} \cdot \exp (6900 / \mathrm{T})^{\mathrm{d})} \text { for ACN } & \text { this work }
\end{array}
$$

${ }^{\text {a) }}$ constant measured by dilatometry ${ }^{\mathrm{b})}$ constant measured by DSC ${ }^{\mathrm{c})} \mathrm{T}$ in ${ }^{\circ} \mathrm{C}^{\mathrm{d})} \mathrm{T}$ in $\mathrm{K}$

BMA was mass polymerized at different temperatures between 60 and $80^{\circ} \mathrm{C}$ with $12 \times 10^{-3}$ mol.l-1 of AIBN.

The differential equation (21) - (23) were numerically simultaneously solved by using fourth order Runge-Kutta method. The values of the four parameters were evaluated using Newton Raphson algorithm by minimizing the function:

$$
\sum_{i=1}^{N \text { (meas.) }} \frac{\left(x_{\text {calc. }}-\mathrm{x}_{\text {meas. }}\right)^{2}}{\left.\mathrm{~N}_{(\text {meas. }}\right)}
$$

Where $\mathrm{x}_{\text {calc }}, \mathrm{x}_{\text {meas }}$. and $\mathrm{N}_{\text {meas }}$ are respectively the conversion calculated, measured and the number of measured points. 
The figure 4 illustrates the comparison of the computed values of butyl methacrylate conversion with those experimentally collected.

This model fitted the data very well and justified it use to optimize the initiator concentration and the reaction temperature. The best values of the four parameters are $\underset{\mathrm{p}}{\mathrm{V}^{*}}=0.33, \mathrm{v}_{\mathrm{t}}^{*}=1.69$ $\mathrm{k}_{\mathrm{pD}}^{0}=3.35 \times 10^{5} \mathrm{~L} \cdot \mathrm{mol}^{-1} \cdot \mathrm{s}^{-1}$ and, $\mathrm{k}_{\mathrm{tD}}^{0}=2.9 \times 10^{13} \mathrm{~L}^{\mathrm{m}} \mathrm{mol}^{-1} \cdot \mathrm{s}^{-1}$

\section{Simulation}

The kinetic results obtained in this study allow a simulation of the reaction under different conditions like initiator concentration, temperature and with the use of initiators mixtures.

In figure 5 is presented the effect of temperature on the conversion of BMA initiated with AIBN at 600 seconds. This time represents the minimum residence time in the extruder with the chosen screw profile.

It is important to note that in reactive extrusion, a conversion distribution is obtained. And a total conversion can only be obtained if the conversion corresponding to the minimum reaction time (residence time) is total.

At $100^{\circ} \mathrm{C}$, the reaction is not completed and the initially initiator quantity is not consumed.

At $140^{\circ} \mathrm{C}$, the decomposition of the initiator is very rapid. Under this condition, the radical's concentration is very high and the primary radicals termination occurs by combination. A complete consumption of initiator is obtained prior the total conversion of monomer. These are typical conditions for dead end polymerisation. ${ }^{[14],[15]}$ 
So the AIBN is not adapted to extrusion time. In order to refine the conditions, the effects on conversion of the use of different initiators were simulated. The results of simulation of the conversion at $100^{\circ} \mathrm{C}$ are presented on figure 6. With AIBN, the gel effect increases the reaction velocity and a full conversion is reached more rapidly than in the case where AVN is used. At this temperature, the decomposition of the ACN initiator is too slow and the full conversion is only reached at $3600 \mathrm{~s}$.

No pure initiator is appropriate, so to respect the residence time, around $600 \mathrm{~s}$, and molar mass of the final product, up to $10 \times 10^{4} \mathrm{~g} \cdot \mathrm{mol}^{-1}$, several simulations were made with a combination of initiators. The figure 7 presents an example of simulation of the conversion at $100^{\circ} \mathrm{C}$ and $120^{\circ} \mathrm{C}$ for reaction initiated with $12 \times 10^{-3}$ mol..$^{-1}$ for AIBN and ACN and $6 \times 10^{-3}$ mol. $l^{-1}$ for AVN. These results show that the barrel temperature of the extruder should be fixed between $100^{\circ} \mathrm{C}$ and $120^{\circ} \mathrm{C}$

\section{Reactive extrusion:}

\section{Evolution of the reaction along the extruder}

\section{Residence time distribution}

We showed previously that reactions conducted in batch can be different from those conducted in reactive extrusion only for heterogeneous systems. When the system was 
homogeneous, the reactions conducted by reactive extrusion or in batch leads to the same product $^{[16]}$

The reactive system used in this study is homogeneous and the same kinetic model can be used for reactions in batch and reactive extrusion.

The kinetic study allowed a correct choice of the experimental conditions for reactive extrusion. The barrel temperature was fixed at $100^{\circ} \mathrm{C}$, the throughput at $0.4 \mathrm{~kg} \cdot \mathrm{h}^{-1}$, the screw rotation rate at $72 \mathrm{rpm}$ and the initiators concentration of $12 \times 10^{-3} \mathrm{~mol} . \mathrm{L}^{-1}$ for AIBN and ACN and $6 \times 10^{-3}$ mol. $\mathrm{L}^{-1}$ for AVN

The sampling was carried out at each position where the pressure is sufficient to allow the flow of the polymer and reactive mixture through the barrel orifice. The residence time distributions at different sampling location are given in figure 8 and the mean residence times are shown in table 2 .

Table 2 : residence time distribution (Q: $0.4 \mathrm{~kg} \cdot \mathrm{h}^{-1}, \mathrm{~N}: 72 \mathrm{rpm}$ )

\begin{tabular}{|c|c|c|c|c|c|}
\hline & Zone 3 & Zone 4 & Zone 5 & Zone 7 & Die \\
\hline (min.) & 10.9 & 16.5 & 18.9 & 27.7 & 41.4 \\
\hline$\sigma^{2}\left(\min ^{2}\right)$ & 52.84 & 77.54 & 79.27 & 138.89 & 213.07 \\
\hline$\sigma_{\theta}^{2}$ & 0.45 & 0.28 & 0.22 & 0.18 & 0.124 \\
\hline $\mathrm{Pe}$ & 3.09 & 5.84 & 7.92 & 9.98 & 14.93 \\
\hline
\end{tabular}

As shown in table 2, the mean residence time was particularly important (41 minutes). 
In figure 9, the cumulative distributions along the screw are plotted against the normalized mean residence time at three collection ports and at the die exit. RTD corresponding to plug flow and mixed flow are also indicated. The shape of the curves clearly shows an evolution. Initially the curve approaches that of mixed flow and evolves toward a plug flow.

The final mean residence time and the evolution of the cumulative distribution can be explained by the unusual extrusion conditions. In non reactive extrusion, the material is fed into the extruder in a solid state (pellets). The solids convoying process is driven by the flights of the rotating screw and by the frictional forces on the barrel surface. ${ }^{[17]}$ So the velocity of a polymer element is proportional to the screw rate. In this study the material is fed in a liquid state. In the first four zones of the extruder, the reactive mixture is essentially composed of polymer dissolved in monomer of very weak viscosity. As shown on the figure 10 , in zone 4 , the conversion is only 0.5 . The consequence is that it slips on the barrel wall and is not pushed by the flights of the screw. It results a very low effectiveness of convoying which is amplified by the presence of a reverse screw element in zone 4. This element produces a backpressure by convoying in a reverse direction. The forward - convoying screw elements must overcome the resistance imposed by this element. It results a degree of fill of $100 \%$, in the first four zones. These conditions increase the residence time and the intensity of the mixing, represented by a weak Pe number (table 2). So the four first zones of the extruder behave like a perfectly mixed reactor. 


\section{Calculated and experimental conversion distribution along the extruder screw}

The RTD describes the history of the polymer or monomer inside the extruder. By combining it with the kinetic of the reaction, the residual concentration of the monomer can be calculated by summing over the RTD: ${ }^{[5], ~[7], ~[17] ~}$

Using a kinetic model developed in the precedent part, the monomer concentration at different reaction times $(\mathrm{M}(\mathrm{t}))$ can be calculated. Combining $\mathrm{M}(\mathrm{t})$ to the $\mathrm{RTD}(\mathrm{E}(\mathrm{t}))$, monomer concentration (A) can be calculated by Equation 30

$A=\sum_{0}^{\infty} M(t) E(t) d t$

M(t) was calculated using two methods. The first one without gel effect, noted WGE model. The second one with gel effect noted GE model.

A calculation example using the RTD data of zone 4 and the two kinetic models is presented in figure 10. The comparison of the shape of the monomer concentration distribution, exhibits an important difference. With the GE model, after 12 minutes the conversion of the monomer is total. Whereas there is $25 \%$ of residual monomer with WGE model.

The figure 11 presents the application of this concept to the RTD data obtained in zones 3,4,5, 7 and at the die combined to the kinetic models. These data were compared with the experimental conversion. 
For positions 3 and 4, a good concordance between the measured data and those calculated is noted without the gel effect model (WGE) whereas the value at the exit of the extruder is in good agreement with the gel effect model value (GE).

Generally, the gel effect is observed when the segmental and translational diffusions decrease as a result of a viscosity increase of the reactive mixture. The use of an extruder reduces the gel effect phenomenon by a reduction of the viscosity: The flow conditions during extrusion have as consequence that entities of different ages coexist in the same points of the barrel. The monomer being the solvent of polymer, the viscosity of the reactional medium remains low. In addition, the effect of shearing, created by the rotational of the screws in the barrel, also decrease the viscosity by limiting the entanglements of the macromolecules. This can explain why the WGE model model fits well the experimental data in positions 3 and 4.

\section{Effect of the screw rotation rate}

In this part the influence of the screw rotation rate on the residence time, the conversion and the weight average molar mass of the obtained polymer are studied. The throughput was fixed at $0.4 \mathrm{~kg} \cdot \mathrm{h}^{-1}$ and the temperature of the barrels was $100^{\circ} \mathrm{C}$.

Because of its importance in extrusion process, the screw rate effect has been widely studied.

Allison ${ }^{[18]}$,Altomare and Ghossi, ${ }^{[19]}$ Ye et al. ${ }^{[20]}$ and Hu and Kadri ${ }^{[21]}$

reported a decrease of the mean residence time when the screw rate increased. Kao and Allison ${ }^{[19]}$ showed that the residence time in corotating twin screw extruder and the degree of 
fill are strongly linked to the screw rate : when the rotation rate increased the degree of fill and the mean residence time decreased.

An increase of the screw rate from 75 to 150 rpm leads to a reduction of the mean residence time up to $30 \%$. It is important to note that $\overline{t_{m}}$ remained unchanged when the screw rate increased from 150 to $200 \mathrm{rpm}$. Under the used extrusion conditions, the viscosity of the blend is very low and the transport is not very efficient. Van Zuilichen et al. ${ }^{[22]}$ pointed out that high screw rate resulted in more slip and so favored back leakage. So an increase of the screw rotation rate, from 150 to 200 rpm, has no effect on the filled length of screw and therefore on the residence time.

The effect of the increase of the screw rate is more pronounced on the residence time distribution: The normalized spread increased with a screw rate increase (table 3). The cumulated curve $F(\theta)$, figure 12, calculated for a screw rate of $75 \mathrm{rpm}$, approaches plug flow type while the curve for the screw rates of 150 and 200 rpm approaches mixed flow type (figure 13). These results are confirmed by the decrease of the Pe number (table 3) : with an increase in screw rate, more mixing is created.

After the reverse screw element the viscosity of the material is sufficiently important to improve the efficiency of the transport. Residence time distributions, measured at the die, are narrower than those obtained at the fourth zone (table 3). For each screw rate, the flow approaches the perfectly mixed flow. At $200 \mathrm{rpm}$, the slightly increase of the residence time 
could be explained by the increase of the shear rate and also of the material temperature due to the viscous dissipation. These conditions induced a viscosity drop and an increase of the filled length.

Table 3 : residence time distribution (Q: $0.4 \mathrm{~kg} \cdot \mathrm{h}^{-1}, \mathrm{~T}: 100^{\circ} \mathrm{C}$ )

\begin{tabular}{|c|c|c|c|c|c|c|}
\cline { 2 - 7 } \multicolumn{1}{c|}{} & \multicolumn{3}{c|}{ Zone 4 } & \multicolumn{3}{c|}{ Die } \\
\hline Screw rate & $75 \mathrm{rpm}$ & $150 \mathrm{rpm}$ & $200 \mathrm{rpm}$ & $75 \mathrm{rpm}$ & $150 \mathrm{rpm}$ & $200 \mathrm{rpm}$ \\
\hline$\overline{t_{m}}$ (min.) & 14.3 & 10.1 & 10.9 & 34.7 & 26 & 27.5 \\
\hline$\sigma^{2}\left(\mathrm{~min}^{2}\right)$ & 40.5 & 49.6 & 72.3 & 120.4 & 152.6 & 154 \\
\hline$\sigma_{\theta}^{2}$ & 0.198 & 0.486 & 0.604 & 0.1 & 0.225 & 0.203 \\
\hline $\operatorname{Pe}$ & 9 & 2.68 & 1.75 & 18.9 & 7.75 & 8.7 \\
\hline
\end{tabular}

In the literature, a few studies have been published about the influence of the shear rate on the kinetics reaction. Only Jansen ${ }^{[23]}$ showed that the gel effect was reduced when the rate of shearing increased.

Thus the conversion evolution should tend towards the results obtained with WGE model. The figure 14 shows, on the contrary, that the experimental and calculated conversion with the model presents a similar evolution.

This evolution of experimental conversion can be explained by the increase of the melt temperature by viscous dissipation resulting of the increase of the rotation rate. The effect of the reduction in the residence time on the conversion is compensated by the temperature. 
The reduction in the molar mass when the rotation rate increases, presented on figure 15 , is in good agreement with this explanation.

\section{Effect of barrel temperature}

The effect of the barrel temperature was studied. The throughput and the rotation rate were respectively fixed at $0.4 \mathrm{~kg} \cdot \mathrm{h}^{-1}$ and $72 \mathrm{rpm}$. To create a plug in the reverse screw element the four first zones were kept at a constant temperature $\left(100^{\circ} \mathrm{C}\right)$. To simplify the notation, these zones are noted part $\mathrm{A}$ in table 4.

The part B is constituted of the fifth last zones and the die. The regulation temperature of this part is given in table 4.

: Temperature profile of the barrel $\left({ }^{\circ} \mathrm{C}\right)$

\begin{tabular}{ccc}
\hline Experiments & Part A & Part B \\
\hline 1 & 100 & 90 \\
2 & 100 & 100 \\
3 & 100 & 125 \\
4 & 100 & 130 \\
5 & 100 & 140 \\
\hline
\end{tabular}


The effect of temperature is complex to analyze and different factors must be considered. 1 The first parameter is the conversion. As shown in figure 16, an increase of the temperature of the part B leads to a slight decrease of the conversion, varying between $99 \%$ to $97 \%$.

2. The second point is the molar mass. This factor shows a particular evolution. The weight average molar mass evolution with temperature shows a minimum. For the lowest values of the barrel temperature an increase of ten degrees leaded to a decrease of the molar mass. In the case of radical polymerization, the molar mass of the polymer is dependent of the gel effect and the instantaneous concentration of the macroradicals.

Since the temperature of zone A is keep constant, the calculation of the concentration for each initiator at the end of the zone 4 was carried out using equation 30 . The average conversions are $0.99,0.66$ and 0.09 for respectively AVN, AIBN and ACN. So AVN is nearly completely vanished in Part A. In Part B during the remaining mean residence times in the several experiments, only AIBN and ACN are still active. The decrease in molar mass from 90 to 100 ${ }^{\circ} \mathrm{C}$ may be due to the increased temperature in B. At $125^{\circ} \mathrm{C}$ and higher AIBN is very rapidly consumed and its contribution to initiation can be neglected in part B. ACN is the only initiator of importance.

An increase in the temperature of the zone B led to a reduction of the concentration in radicals and thus an increase of the molecular weight. 
3. The last factor is the residence time. The decrease of the residence time (figure 17) can be explained by the increase of the viscosity and so the decrease of the filled length.

\section{Conclusions}

The kinetic modelling is a good tool to surround the extrusion conditions like temperature and initiator type and concentration. The polybutylmethacrylatre can be produced by reactive extrusion. Due to the low monomer viscosity and polymerisation the throughput is limited. The temperature of extruder and rotation screw rate must be kept at a low value to maximize the residence time of the material. In these conditions the conversion reaches $98 \%$. The effect of extruder parameters is very important on the weight average molar mass of the polymer.

Finally, by using this screw profile, it is possible to produce a polymer with a low concentration of residual monomer, high weight average molar mass and good optical properties.

The extruder used in this study is devoted to research. Many reactive or non reactive systems are extruded using this device. Even if completely cleaned after use, some residual impurities are still present within the extruder. These impurities can dramatically change the optical properties of the obtained fibres making impossible a correct comparison with fibres made by batch reaction.

Nevertheless, the fibres prepared by batch reaction or by reactive extrusion have the same structure, there is no residual monomer and the molar masses are equivalent. One can 
reasonably consider that if an extruder devoted only for the preparation of optical fibres is used, the optical properties of the issued optical fibres will be identical to the properties of fibres prepared by batch reactions.

From the conditions defined it was possible to finalize optimal conditions allowing synthesizing a material having a weak attenuation in the field of the visible 


\section{References}

[1] M. Xanthos, Reactive Extrusion, Hanser Publishers, New York, 1992.

[2] G. Illing, Modern Plastics,1969, 8, 70.

[3] W. Michaeli, H. Höcker, U. Berghaus and W. Frings, J. App. Polym. Sci., 1993, 48, 871.

[4] G. Menges, T. Bartilla, Polym. Eng. Sci., 1987, 27, 1216.

[5] Y. Chalamet, M. Taha, B. Vergnes, Polym. Eng. Sci., 2000, 1, 207.

[6] M.J. Krell , A. Brandolin, E.M. Vallés, Polym. Reac. Eng., 1994, 2, 389.

[7] C. Titier, J. P. Pascault, M. Taha, J. App. Polym. Sci., 1996, 59, 415.

[8] G.H. Hu, I. Kadri, C. Picot, Polym.Eng. Sci., 1999, 39, 930.

[9] Y. Takezawa, N.Taketani, S. Tanno, S. Ohara, J. App. Polym. Sci., 1992, 46, 1835.

[10] Y. Takezawa, N.Taketani, S. Tanno, S. Ohara, J. Polym. Sci. : Part B: Polym. Phys., 1992, 30, 879.

[11] D. Panke, Makromol. theory simul., 1995, 4, 759 .

[12] F.L. Marten, A.E. Hamielec, ACS Symp. Ser., 1979, 104.

[13] M. Buback, Makomol. Chem., 1990, 191, 1575.

[14] A. Tobolsky, J. AM. Chem. Soc., 1958, 80, 5927

[15] A. Tobolsky, C. Rogers, R. Brickman, J. AM. Chem. Soc., 1960, 82, 1277

[16] J. C. David, Y. Chalamet, M. Taha , J. Appl. Polym. Sci. 2004, 92: 2357

[17] J. Yamamuro, D. Penumadu, A. Campbell, Intern. Polym. Proces.,1998, XIII(1), 3 
[18] P. Cassagneau , M. Taha, J. Appl. Polym. Sci., 1996, 60, 1765. [19] S.V. Kao, G.R. Allison, Polym. Eng. Sci., 1984, 24 (9), 645

[19] R.E. Altomare, P. Ghossi, Biotech. Prog., 1986, 2 (3), 157

[20] A. Ye, S. Hwang, S., J. Guo , J. of Food Eng., 1992, 17, 1

[21] G. Hu, I. Kadri, Polym. Eng. Sci., 1999, 39, 2

[22] D.J. Van Zuilichem, J. G. de Swart, G. Buisman, G. Lebensm. Wiss. U. Techn., 1973, 6 (5), 184

[23] M. Cioffi, A.C. Hoffmann, L.P.B.M. Janssen, Polym. Eng. Sci., 2001, 41 (3), 595. 


\section{Figures}

Figure 1 : Screw profile SE/33: screw element/pitch in mm, RSE/25 : reverse screw element/ pitch in mm,KB/90: kneading blocks. The length of each element was $50 \mathrm{~mm}$

Figure 2: Attenuation loss of poly(butyl methacrylate) and poly (2-hydroxy ethyl methacrylate) polymers

Figure 3 : Effect on optical properties of residual BMA monomer and AIBN initiator in PBMA fibber

Figure 4: Comparison between experimental data and calculated (full lines) for butyl methacrylate mass polymerization initiated with $12 \times 10^{-3}$ mol. $\mathrm{L}^{-1}$ initiator $\mathrm{AIBN}\left(\square 60^{\circ} \mathrm{C}\right.$, ॰ $\left.70^{\circ} \mathrm{C}, \Delta 75^{\circ} \mathrm{C}, \circ 80^{\circ} \mathrm{C}\right)$

Figure 5: Effect of the temperature on the conversion initiated with12 $\times 10^{-3} \mathrm{~mol}_{\mathrm{L}} \mathrm{L}^{-1}$ initiator $\operatorname{AIBN}\left(\square 100{ }^{\circ} \mathrm{C}, \circ 120^{\circ} \mathrm{C}\right.$ and $\left.* 140^{\circ} \mathrm{C}\right)$ 
Figure 6 : simulation of the reaction initiated with the three different initiators: AVN, AIBN, $\mathrm{ACN}$ at $100^{\circ} \mathrm{C}$. The initial concentration of each initiator is $12 \times 10^{-3}$ mol..$^{-1}$

Figure 7 : Calculated data with model for 2 temperature $\square 100{ }^{\circ} \mathrm{C}$, $\circ 120^{\circ} \mathrm{C}$, reaction initiated with $12 \times 10^{-3}$ mol.L-1 $\mathrm{AIBN}, 12 \times 10^{-3}$ mol.L-1 $\mathrm{ACN}, 6 \times 10^{-3}$ mol.L-1 AVN.

Figure 8: Evolution of the residence time distribution along the screw (Q: $0.4 \mathrm{~kg} \cdot \mathrm{h}^{-1} \mathrm{~T}: 100^{\circ} \mathrm{C}$, $\mathrm{N}: 72 \mathrm{rpm}, \mathrm{O}$ RTD in zone 3, $\circ$ RTD in zone 4, $\triangle \mathrm{RTD}$ in zone 5, $\square$ RTD in zone 7 and ${ }^{*}$ RTD at the die).

Figure 9: Comparison of cumulative distribution along the screw (Q: $0.4 \mathrm{~kg} \cdot \mathrm{h}^{-1} \mathrm{~T}: 100^{\circ} \mathrm{C}, \mathrm{N}$ : $72 \mathrm{rpm}, \mathrm{O}$ RTD in zone 3, $\bigcirc$ RTD in zone $4, \triangle \mathrm{RTD}$ in zone 5 and ${ }^{*}$ RTD at the die).

Figure 10: Unreacted monomer concentration calculated from a kinetic model with gel effect (GE model) $(\neg)$ and without gel effect (WGE model) $(-)$ in zone4 
Figure 11: Conversion versus the position along the screw length : $\diamond$ experimental data, $\square$ GE model, and ^ $\_$WGE model (Q: $\left.0.4 \mathrm{~kg} \mathrm{~h}^{-1} \mathrm{~T}: 100^{\circ} \mathrm{C}, \mathrm{N}: 72 \mathrm{rpm}\right)$

Figure 12 Cumulated distribution at different screw rates: $\bullet-75$ rpm, $\square-150 \mathrm{rpm}$ and $\triangle$ 200 rpm (Zone 4, Q: 0.4 kg.h ${ }^{-1}$, T: $\left.100^{\circ} \mathrm{C}\right)$

Figure 13 Cumulated distribution at different screw rates: $\rightarrow 75$ rpm, $\square-150 \mathrm{rpm}$ and $\triangle$ 200 rpm (Die, Q: $\left.0.4 \mathrm{~kg} \cdot \mathrm{h}^{-1}, \mathrm{~T}: 100^{\circ} \mathrm{C}\right)$

Figure 14: Conversion versus the Screw rate : $\diamond$ experimental data, $\square-$ GE model data, and ^ WGE data (Q: $\left.0.4 \mathrm{~kg} \mathrm{~h}^{-1} \mathrm{~T}: 100^{\circ} \mathrm{C}\right)$

Figure 15: Influence of the screw rate on weight average molar mass (Q: 0.4 kg.h-1, T:100 $\left.{ }^{\circ} \mathrm{C}\right)$ Figure 16: Influence of the temperature of the zone 5 to 9 (part B) on conversion $\square-$ and weight average molar mass $\rightarrow\left(\mathrm{N}: 72 \mathrm{rpm}, \mathrm{Q}: 0.4 \mathrm{~kg} \cdot \mathrm{h}^{-1}\right)$

Figure 17: Influence of the temperature of the zone 5 to 9 (part B) on the mean residence time at $\mathrm{N}: 72 \mathrm{rpm}, \mathrm{Q}: 0.4 \mathrm{~kg} \cdot \mathrm{h}^{-1}$. 


\section{Text and graphic for the 'Table of Contents'}

A process for a poly(butyl methacrylate) optical fibers production by twin-screw reactive extrusion was developed. A kinetic model was proposed and the reaction evolution was simulated allowing the choice of reaction conditions in adequation with reactive extrusion technical limitations. The effect of the different kinetic and process conditions on the reaction were analyzed in relation with the residence time distribution.

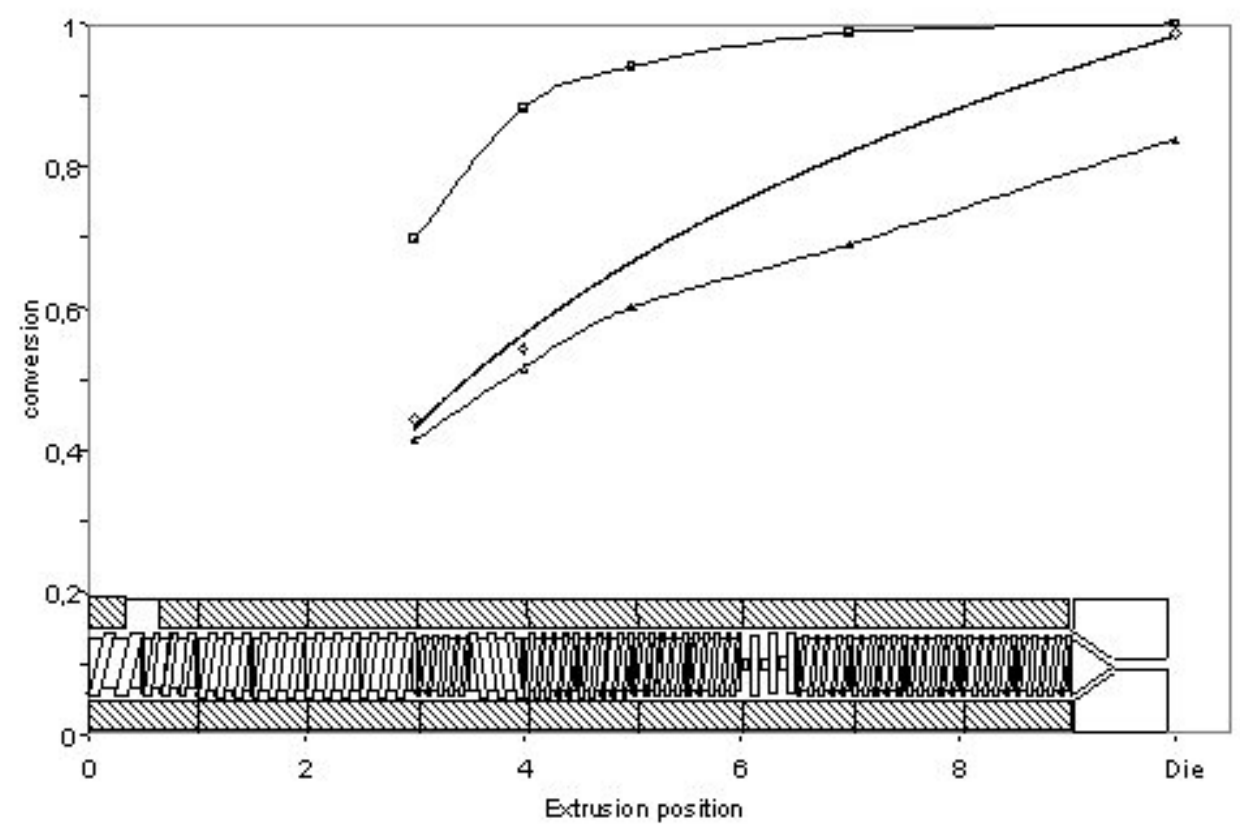




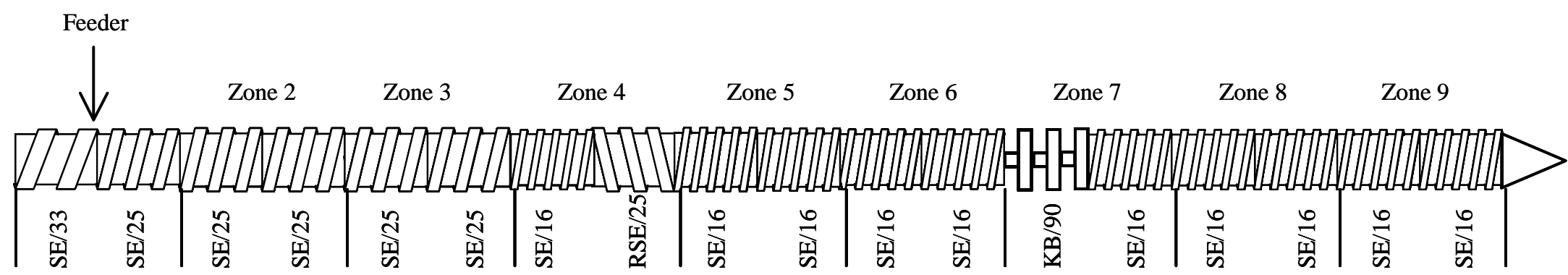

Figure 1 : Screw profile SE/33: screw element/pitch in mm, RSE/25 : reverse screw element/ pitch in $\mathrm{mm}, \mathrm{KB} / 90$ : kneading blocks. The length of each element was $50 \mathrm{~mm}$ 


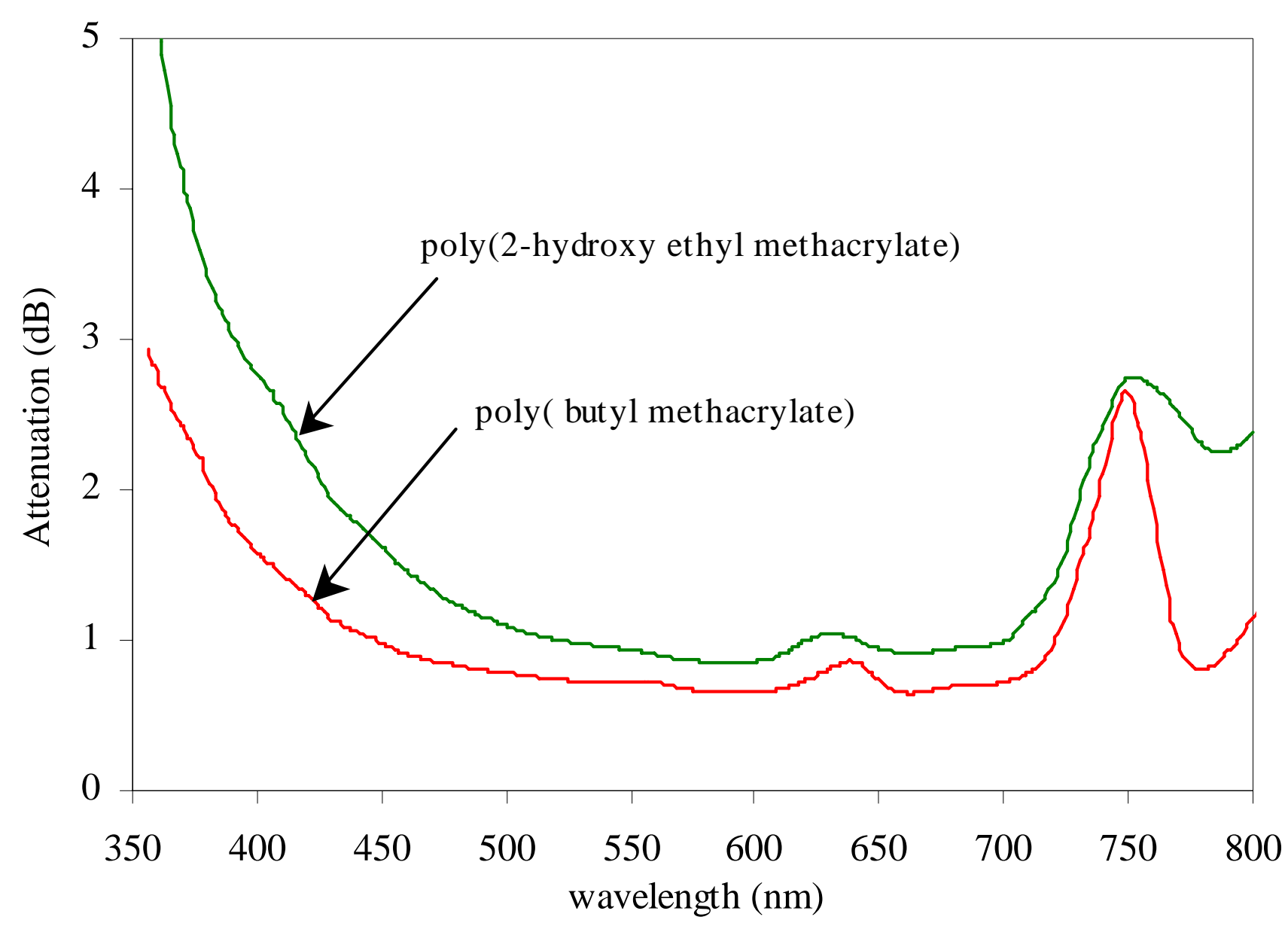

Figure 2: Attenuation loss of poly(butyl methacrylate) and poly (2-hydroxy ethyl methacrylate) polymers 


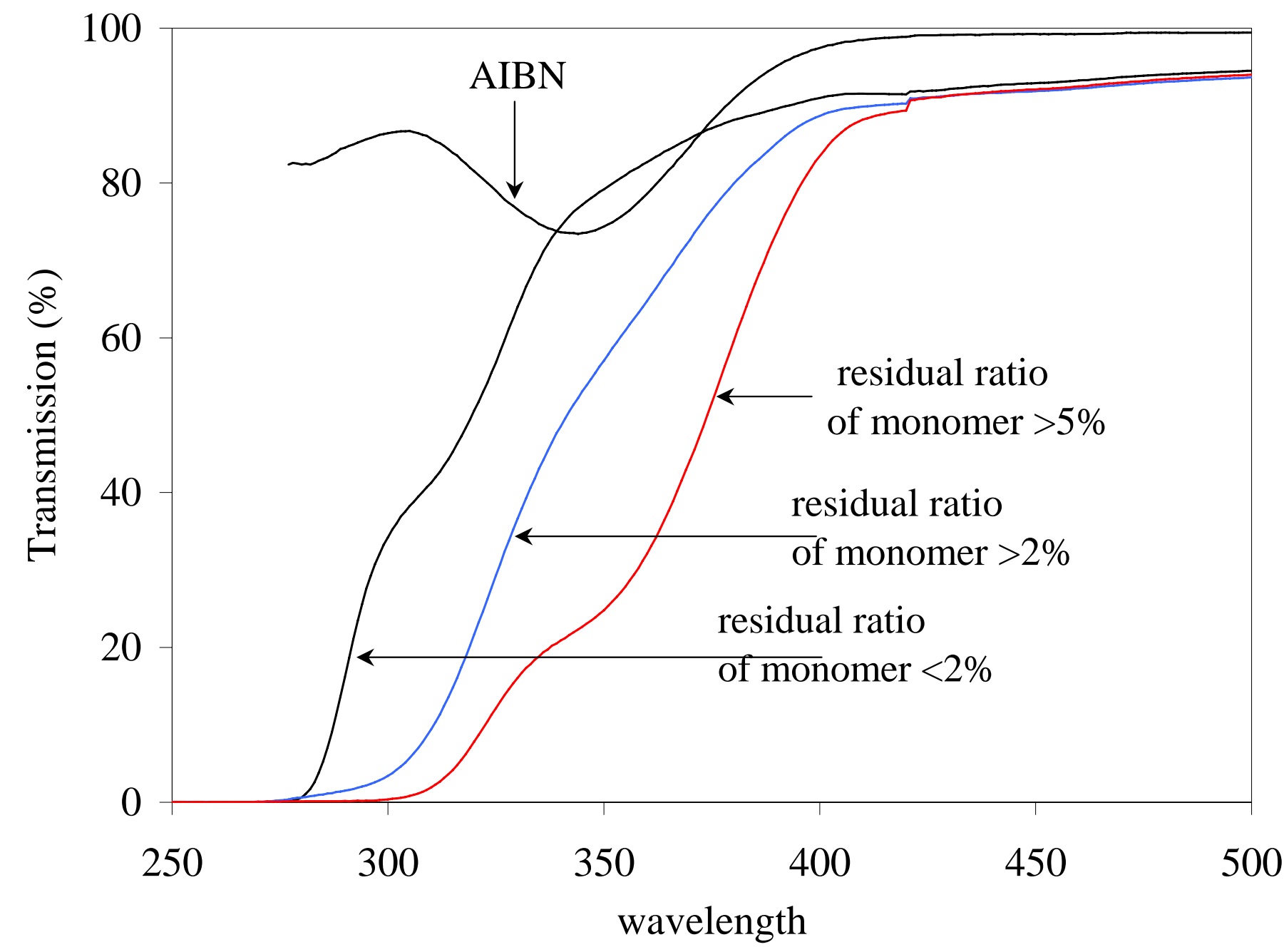

Figure 3 : Effect on optical properties of residual BMA monomer and AIBN initiator in PBMA fibber 


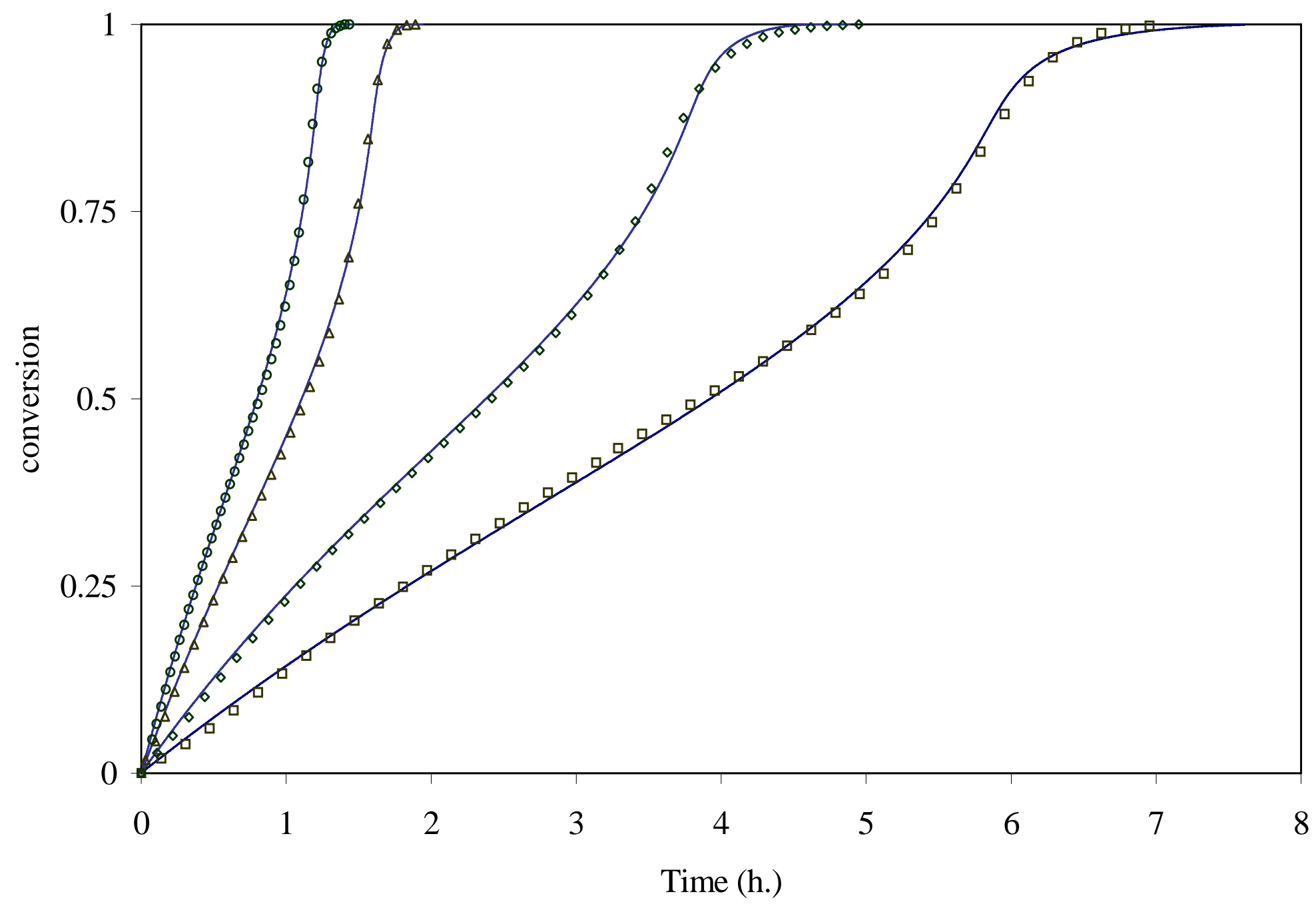

Figure 4: Comparison between experimental data and calculated (full lines) for butyl methacrylate mass polymerization initiated with $12 \times 10^{-3} \mathrm{~mol} . \mathrm{L}^{-1}$ initiator $\mathrm{AIBN}\left(\square 60^{\circ} \mathrm{C}, \diamond 70^{\circ} \mathrm{C}, \triangle 75^{\circ} \mathrm{C}, \circ 80^{\circ} \mathrm{C}\right)$ 


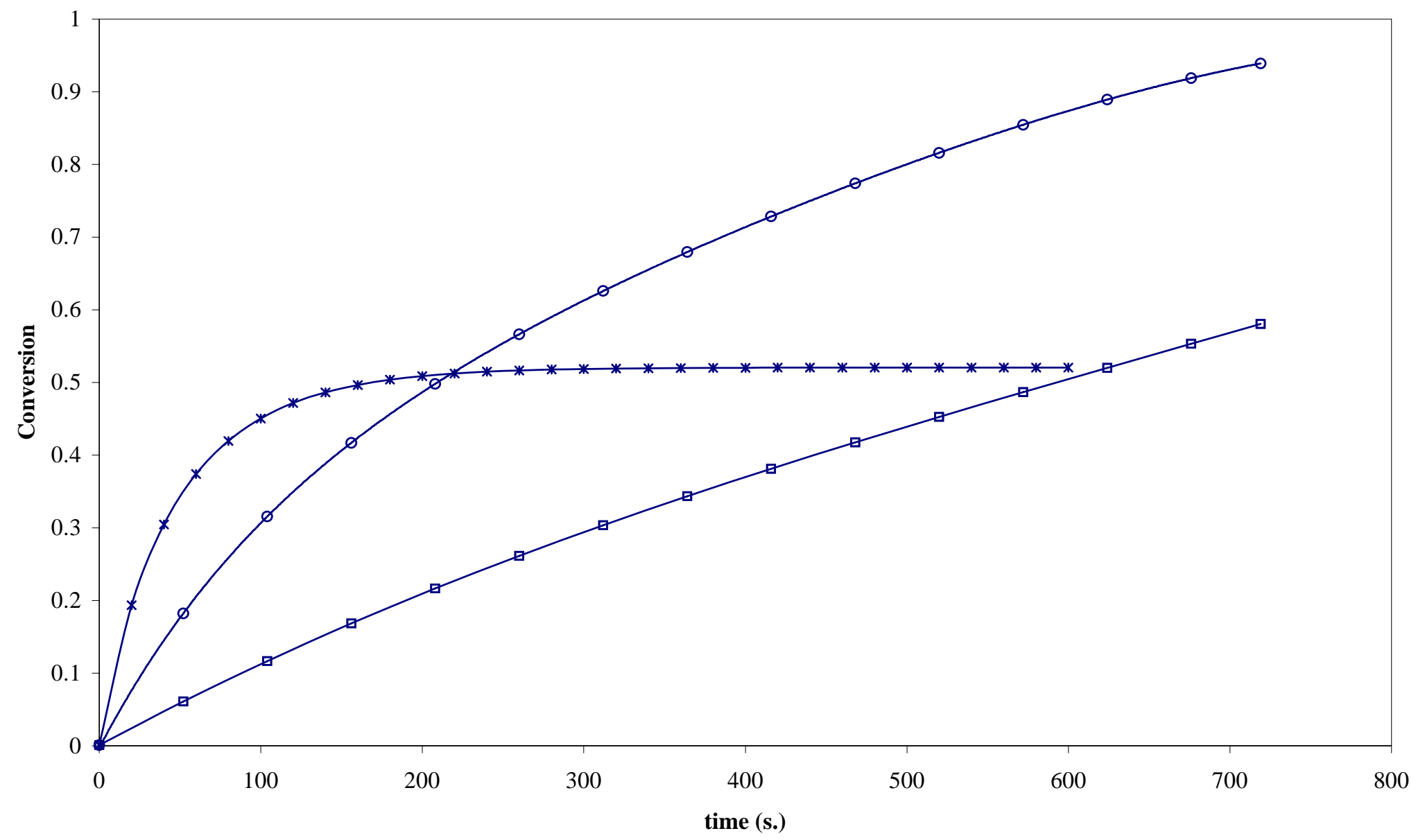

Figure 5: Effect of the temperature on the conversion initiated with $12 \times 10^{-3} \mathrm{~mol}^{-1} \mathrm{~L}^{-1}$ initiator AIBN (口 $100^{\circ} \mathrm{C}, \circ 120^{\circ} \mathrm{C}$ and $* 140^{\circ} \mathrm{C}$ ) 


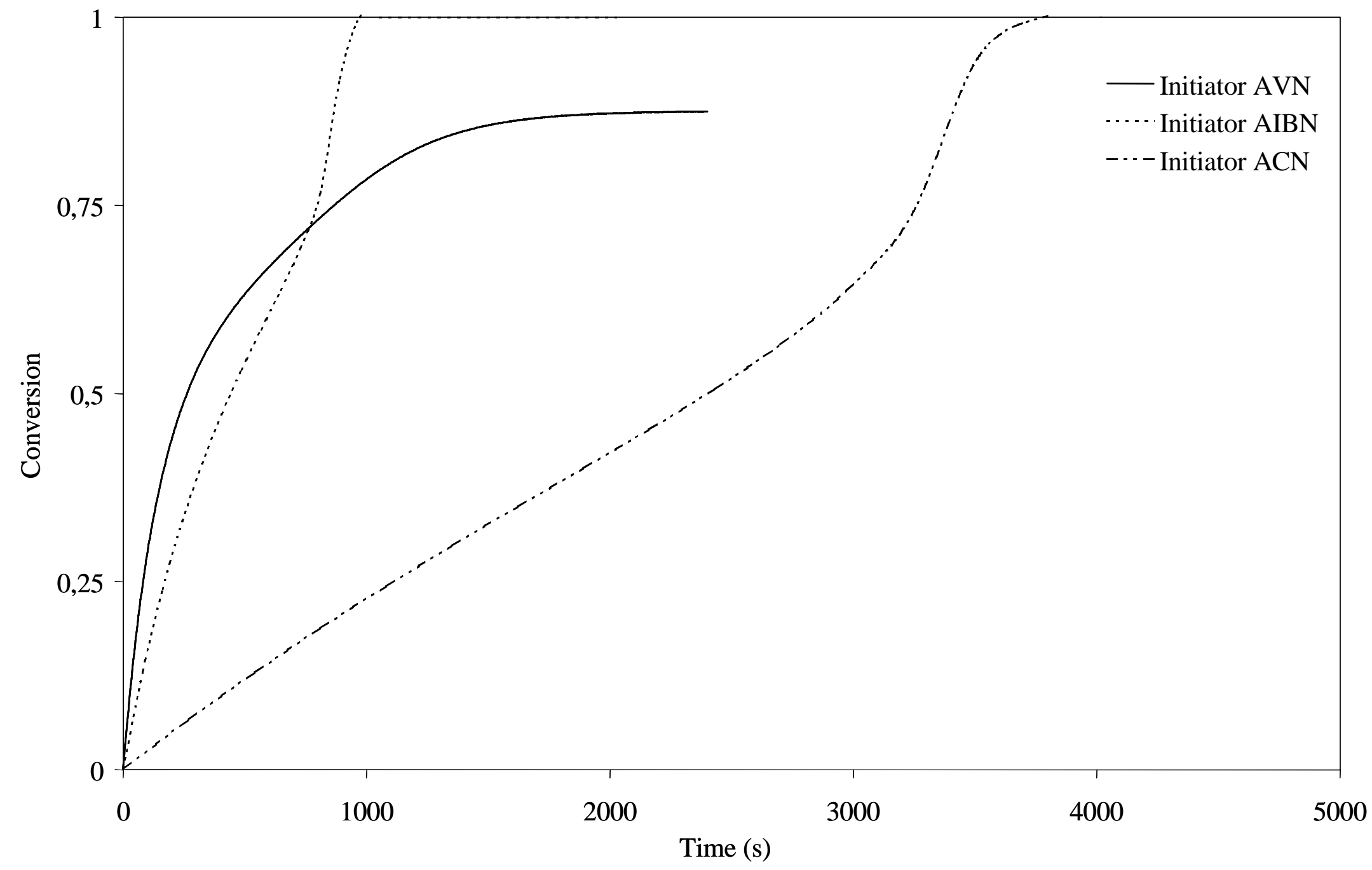

Figure 6 : simulation of the reaction initiated with the three different initiators: AVN, AIBN, ACN at $100^{\circ} \mathrm{C}$. The initial concentration of each initiator is $12 \times 10^{-3} \mathrm{~mol}^{-I^{-1}}$ 


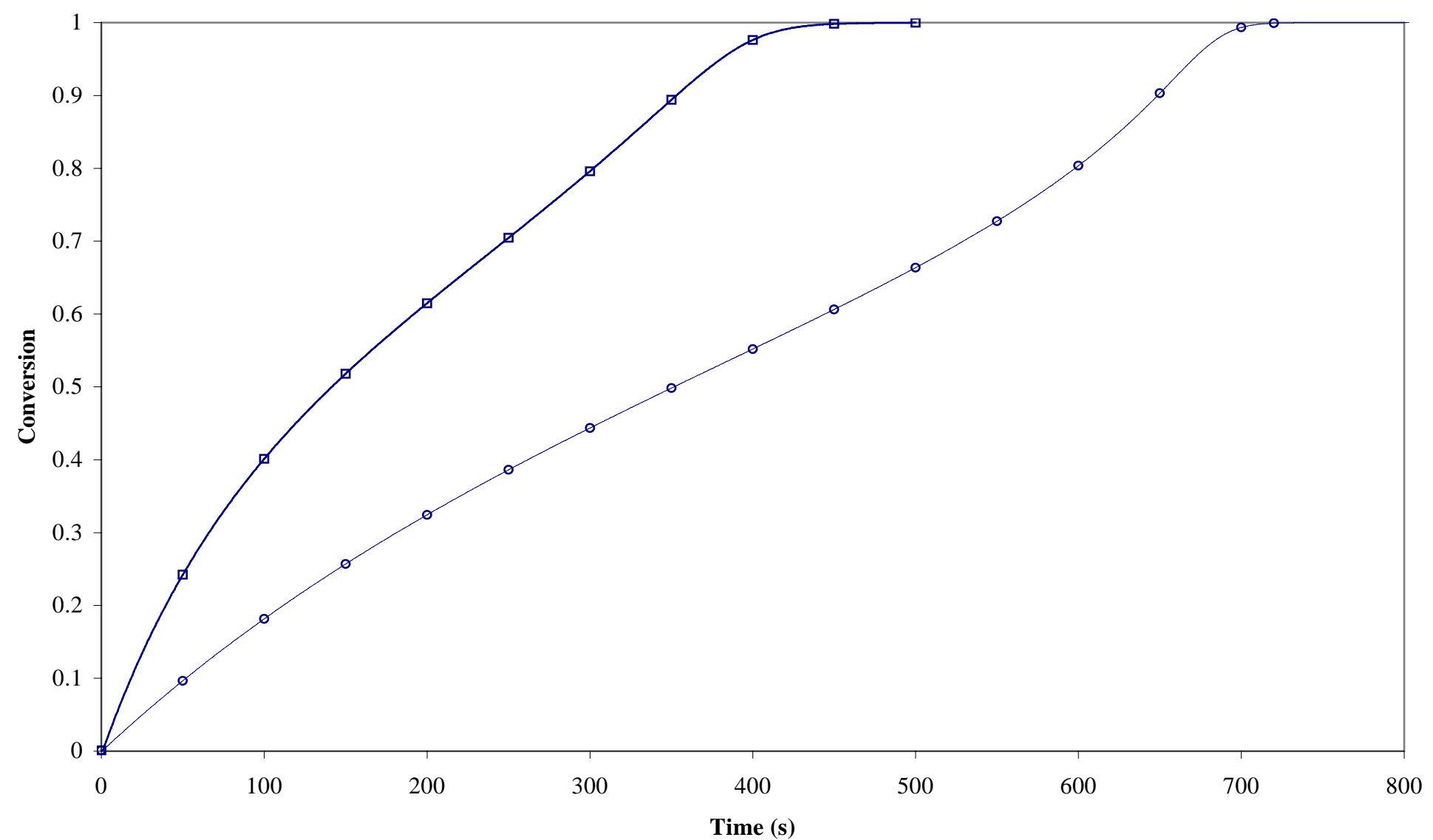

Figure 7 : Calculated data with model for 2 temperature $\square 100^{\circ} \mathrm{C}, \circ 120^{\circ} \mathrm{C}$, reaction initiated with $12 \times 10^{-3} \mathrm{~mol} . \mathrm{L}^{-1} \mathrm{AIBN}, 12 \times 10^{-3} \mathrm{~mol} . \mathrm{L}^{-1} \mathrm{ACN}, 6 \times 10^{-3} \mathrm{~mol} . \mathrm{L}^{-1} \mathrm{AVN}$. 


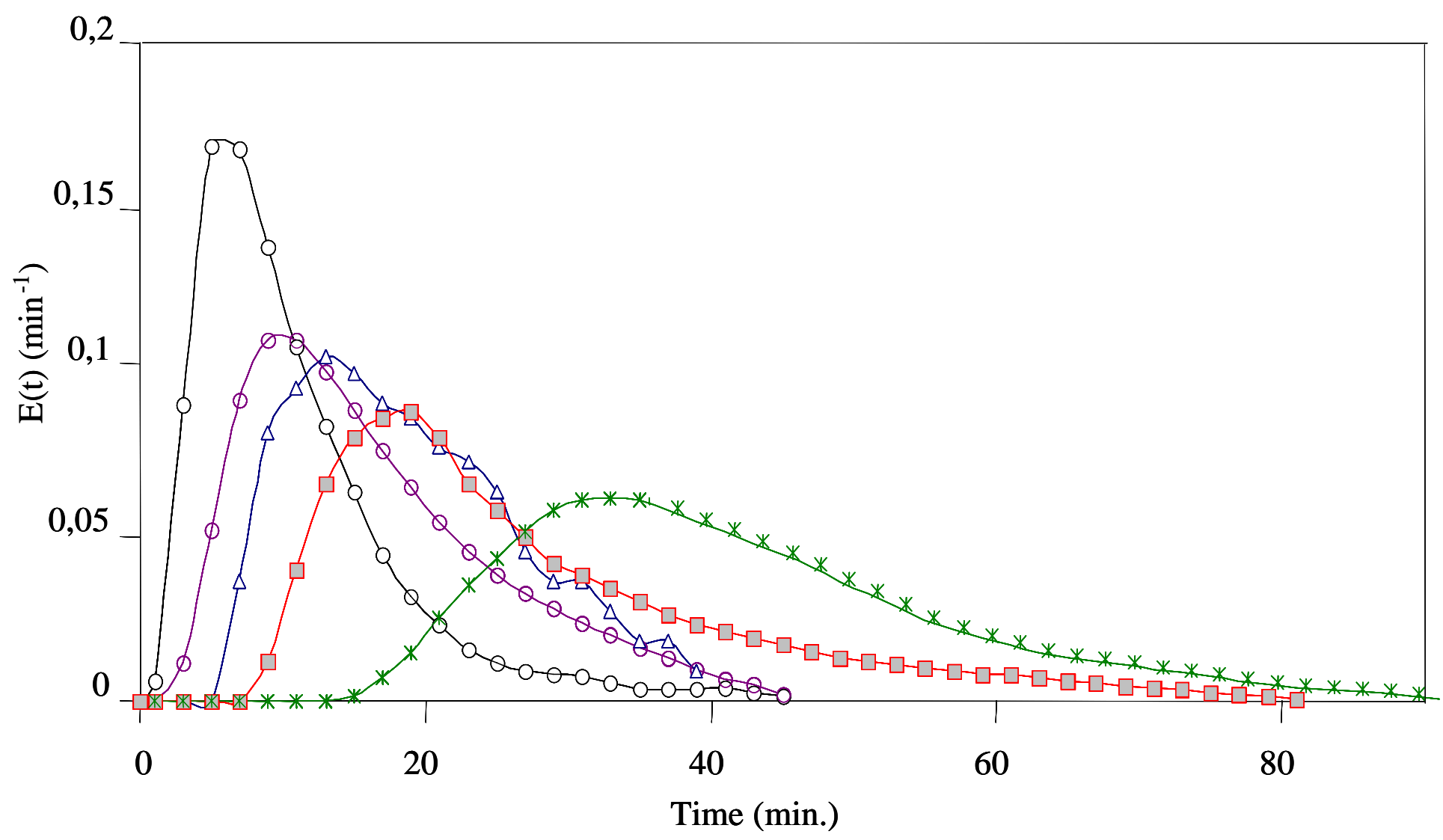

Figure 8: Evolution of the residence time distribution along the screw (Q: $0.4 \mathrm{~kg} \cdot \mathrm{h}^{-1} \mathrm{~T}: 100^{\circ} \mathrm{C}, \mathrm{N}: 72$ rpm, $\circ$ RTD in zone $3, \circ$ RTD in zone $4, \triangle$ RTD in zone $5, \square$ RTD in zone 7 and ${ }^{*}$ RTD at the die). 


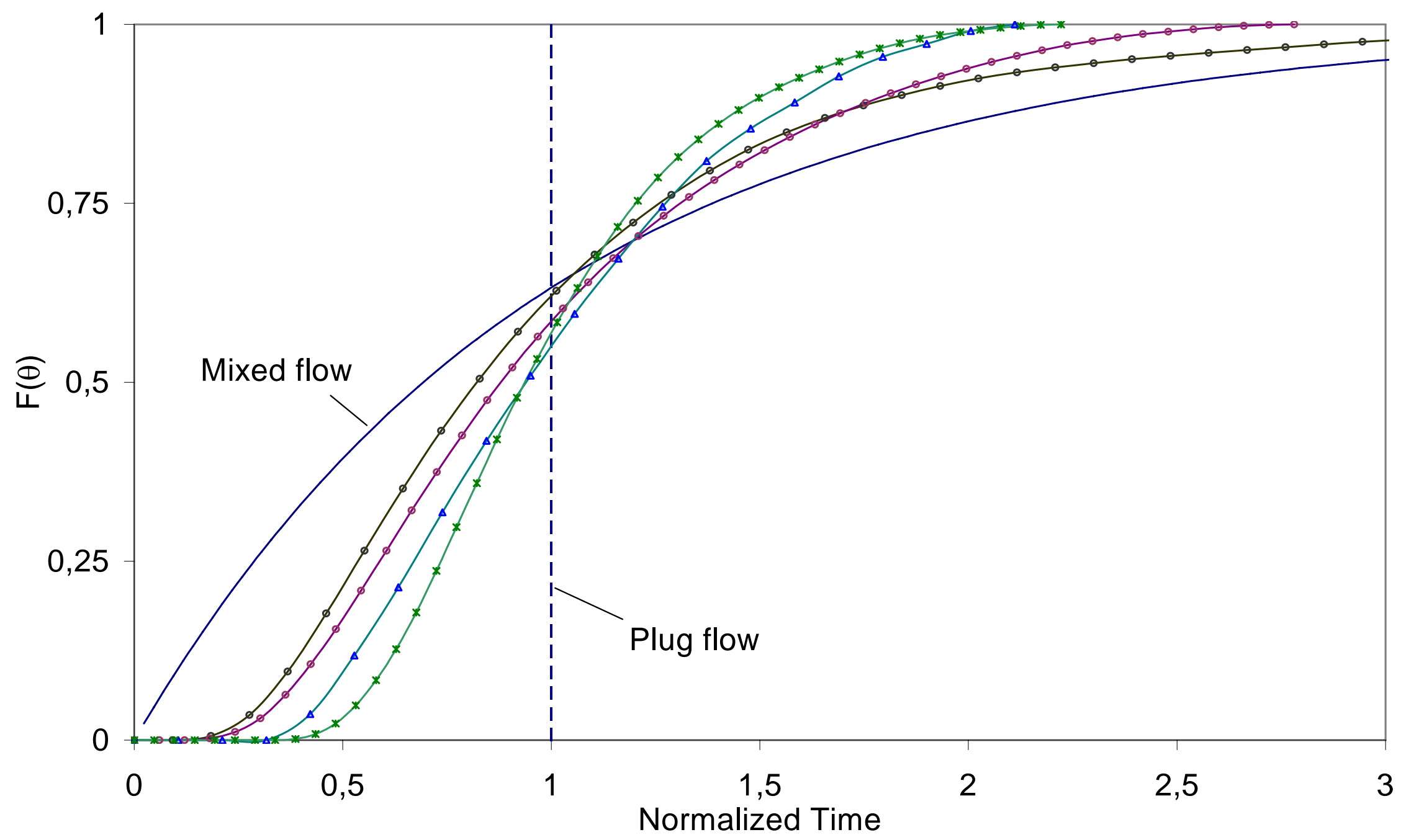

Figure 9: Comparison of cumulative distribution along the screw (Q: $0.4 \mathrm{~kg} \cdot \mathrm{h}^{-1} \mathrm{~T}: 100^{\circ} \mathrm{C}, \mathrm{N}: 72 \mathrm{rpm}$, O RTD in zone 3, O RTD in zone $4, \triangle$ RTD in zone 5 and $*$ RTD at the die). 


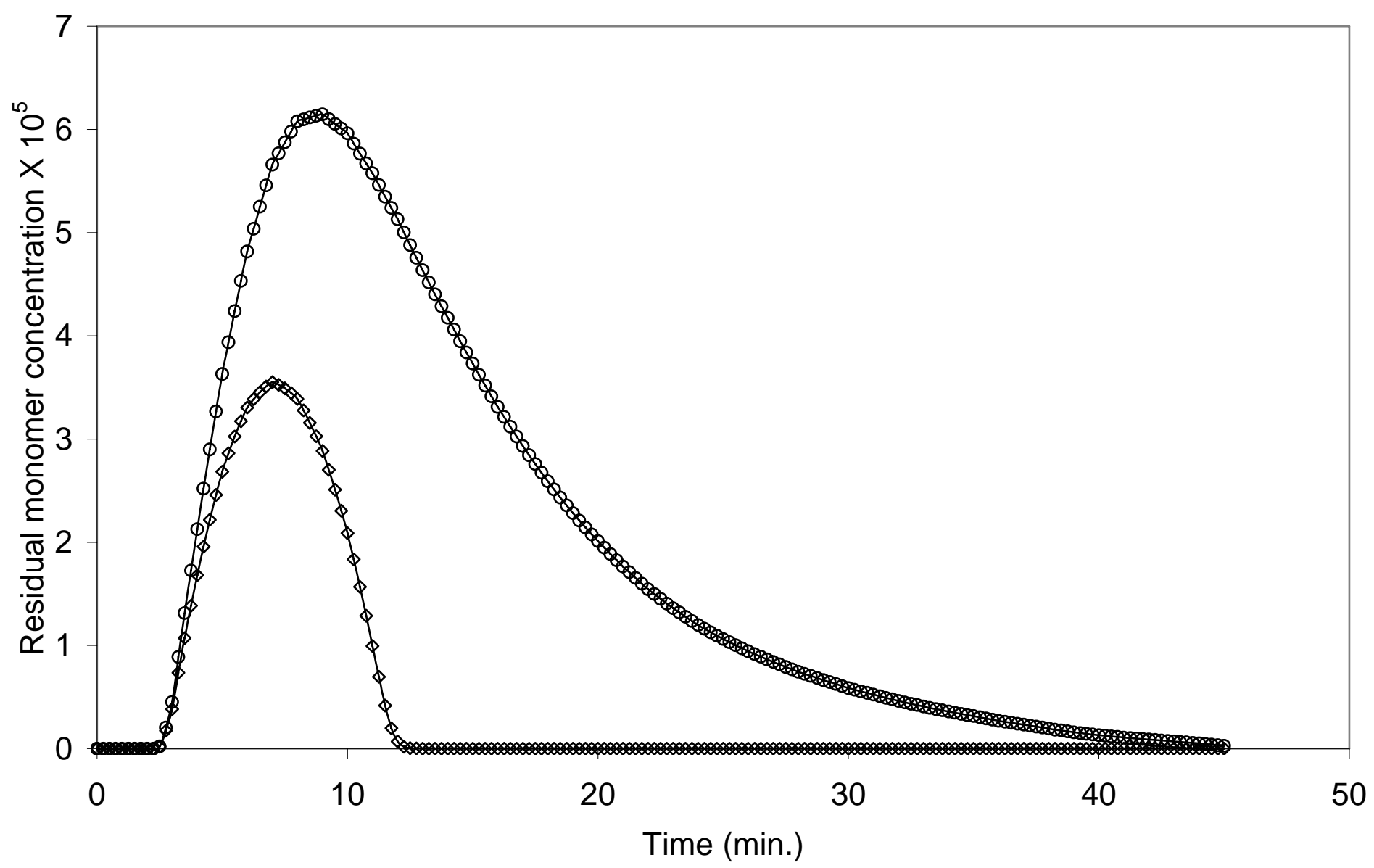

Figure 10: Unreacted monomer concentration calculated from a kinetic model with gel effect (GE model) $(-\rightarrow)$ and without gel effect (WGE model) $(-\odot)$ in zone4 


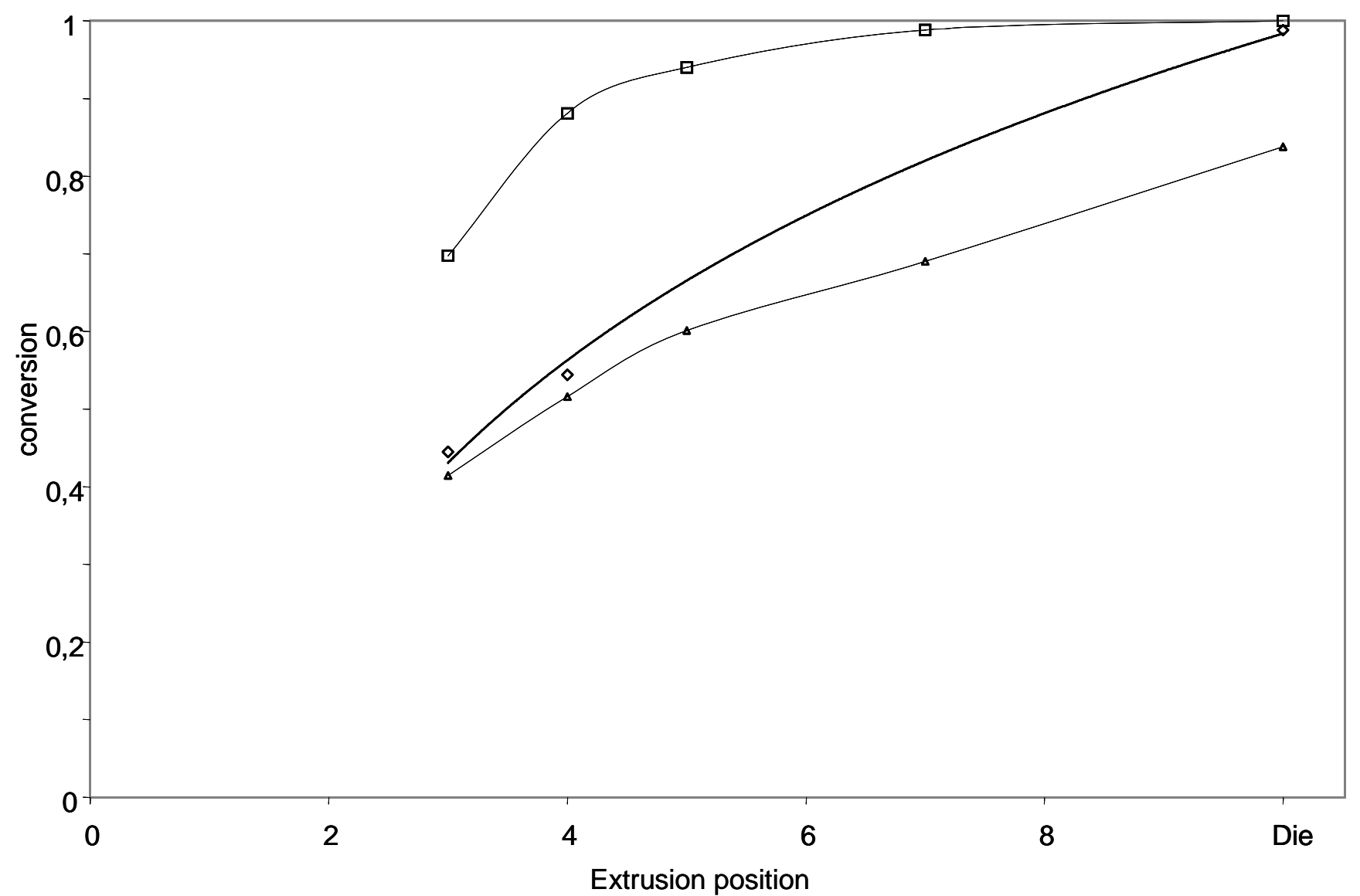

Figure 11: Conversion versus the position along the screw length : $\diamond$ experimental data, $\square-\mathrm{GE}$ model, and $\triangle$ WGE model (Q: $\left.0.4 \mathrm{~kg} \mathrm{~h}^{-1} \mathrm{~T}: 100^{\circ} \mathrm{C}, \mathrm{N}: 72 \mathrm{rpm}\right)$ 


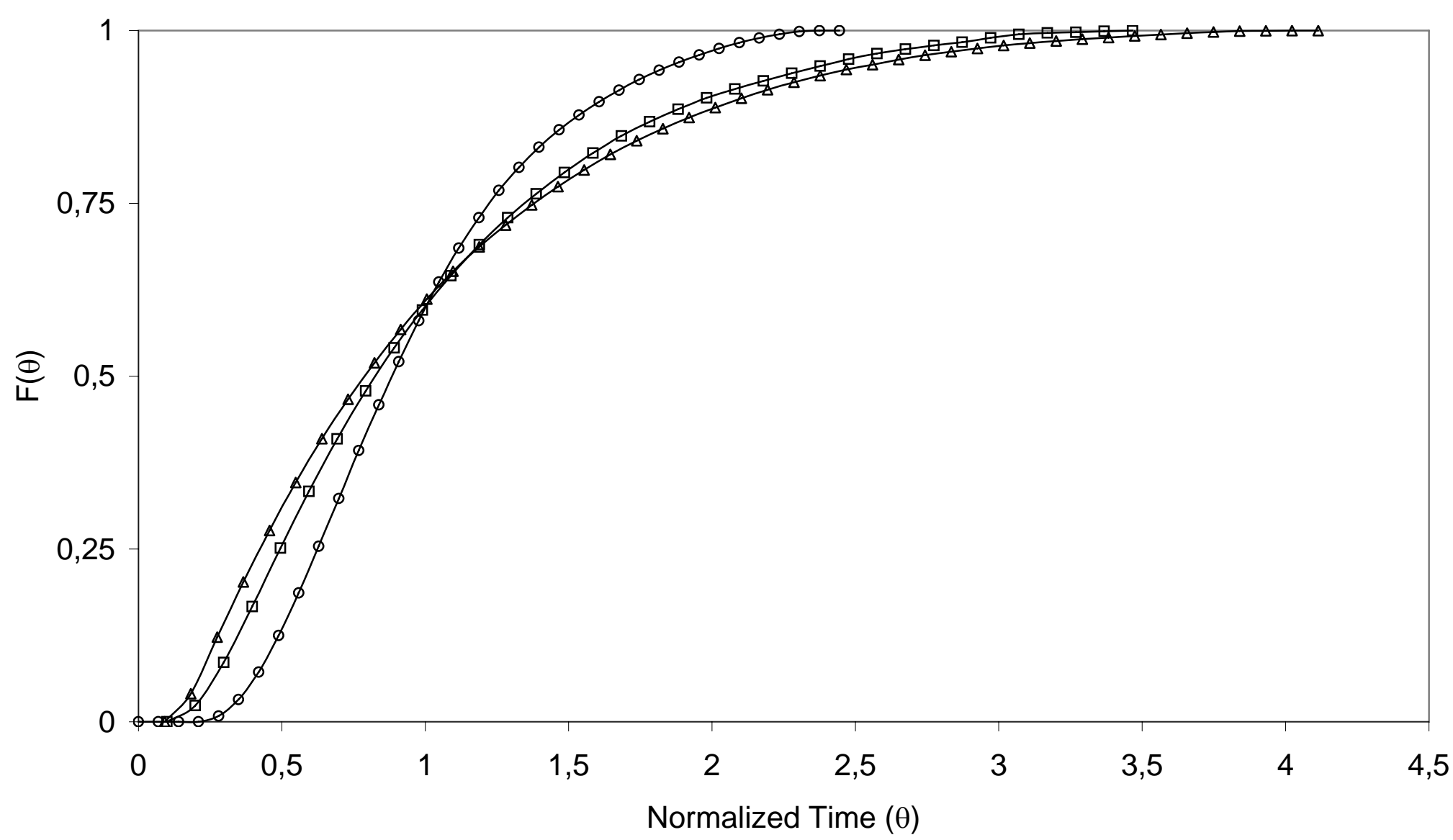

Figure 12 Cumulated distribution at different screw rates: $\multimap 75 \mathrm{rpm}, \square-150 \mathrm{rpm}$ and $\triangle 200$
rpm
(Zone
4
Q:
0.4
$\mathrm{kg} \cdot \mathrm{h}^{-1}$,
$\mathrm{T}$ :
$\left.100^{\circ} \mathrm{C}\right)$ 


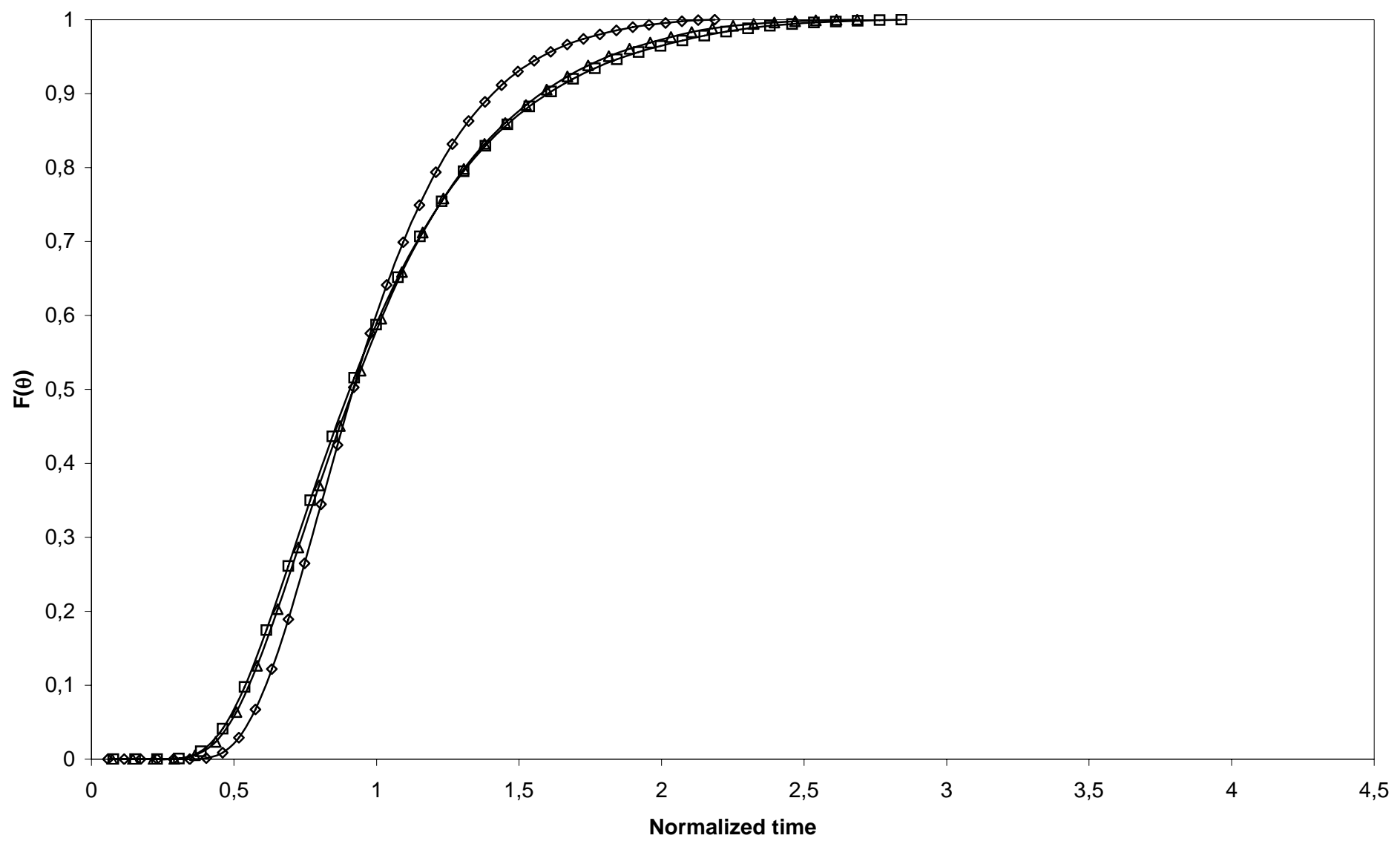

Figure 13 Cumulated distribution at different screw rates: $\neg 75 \mathrm{rpm}, \square-150 \mathrm{rpm}$ and $\triangle-200$ rpm (Die, Q: 0.4 kg.h ${ }^{-1}, \mathrm{~T}: 100^{\circ} \mathrm{C}$ )

13 


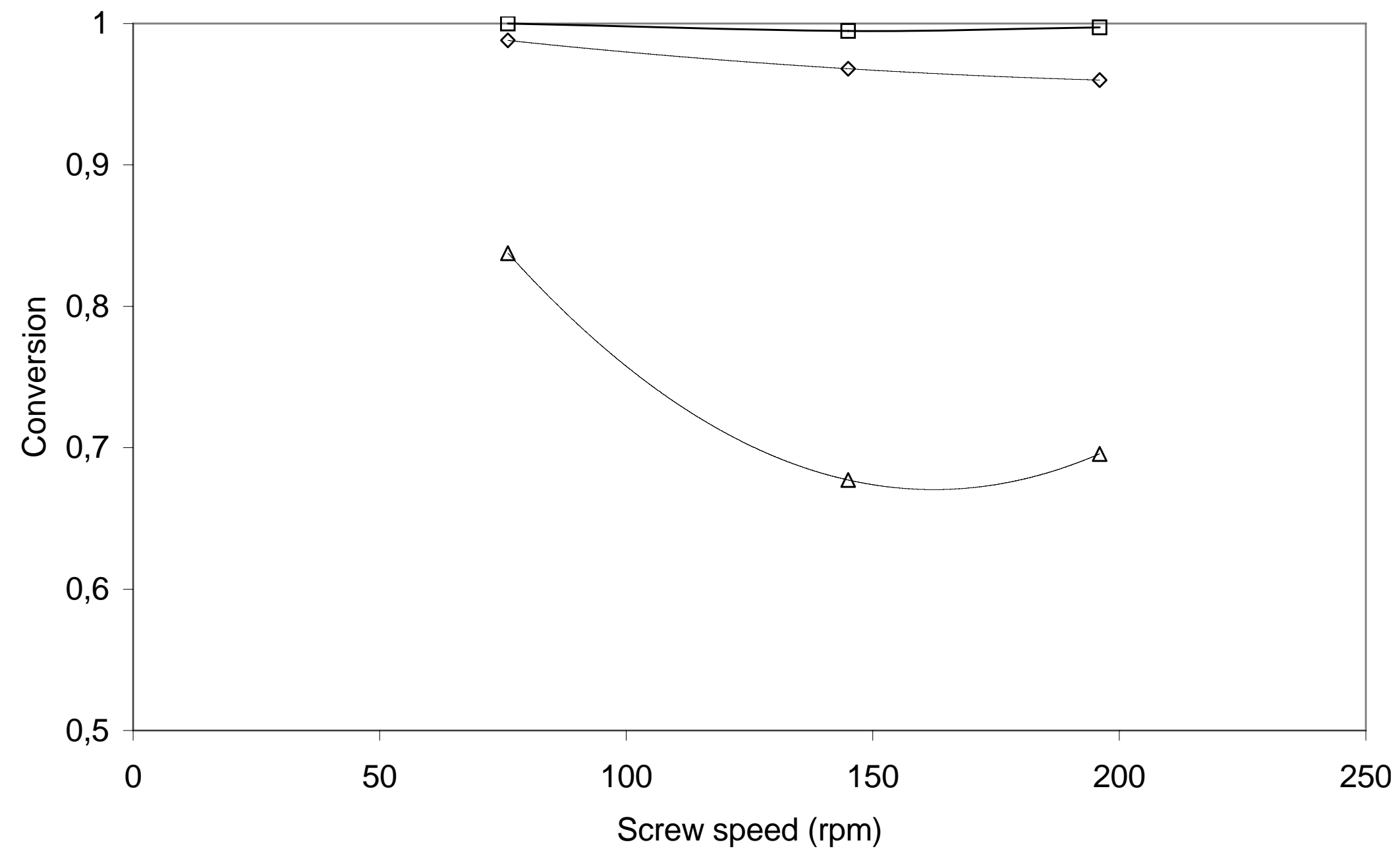

Figure 14: Conversion versus the Screw rate : $\diamond$ experimental data, $\square$ GE model data, and $\triangle$ WGE data (Q: $\left.0.4 \mathrm{~kg} \mathrm{~h}^{-1} \mathrm{~T}: 100^{\circ} \mathrm{C}\right)$ 


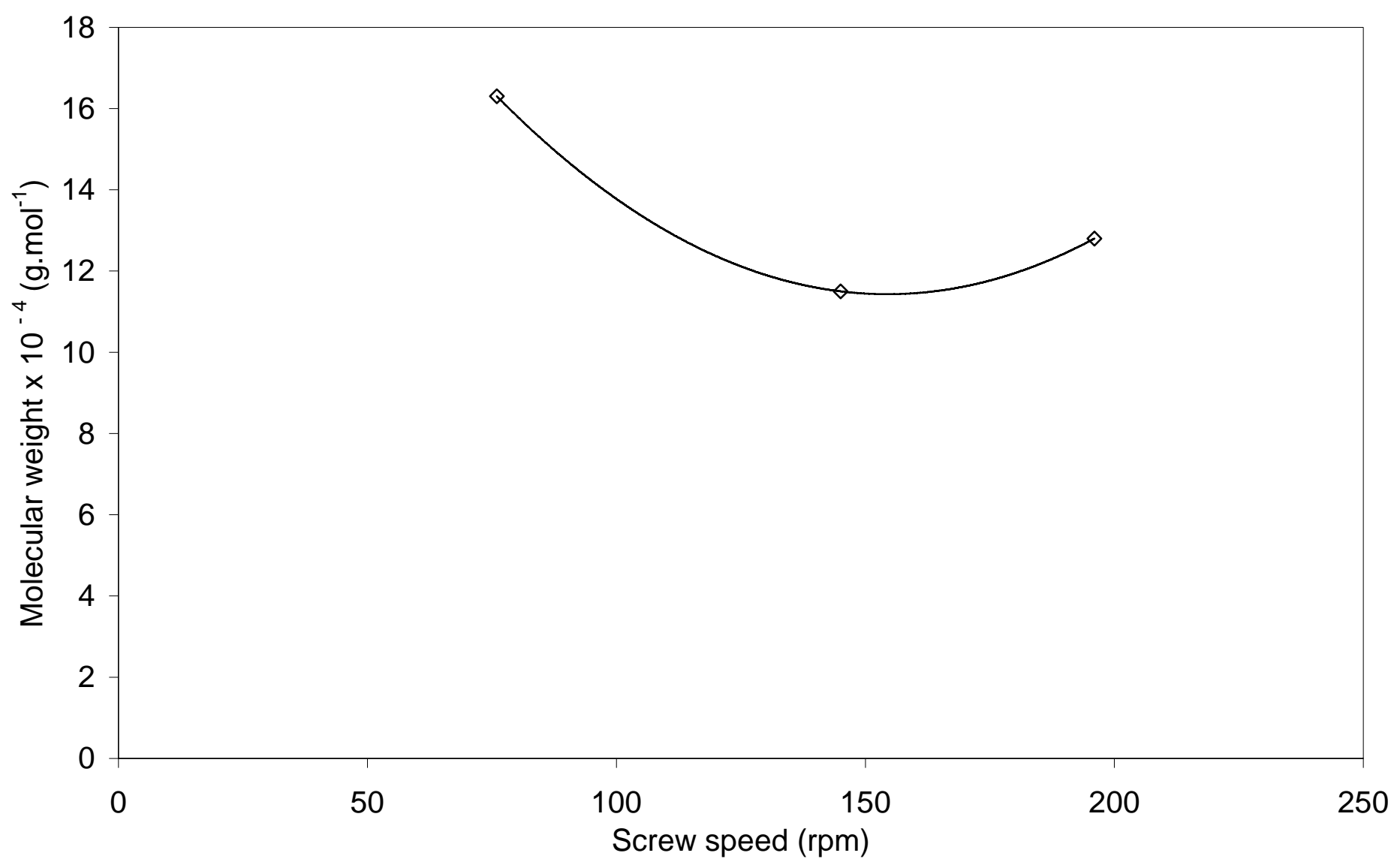

Figure 15: Influence of the screw rate on weight average molar mass (Q: $\left.0.4 \mathrm{~kg} \cdot \mathrm{h}-1, \mathrm{~T}: 100^{\circ} \mathrm{C}\right)$ 


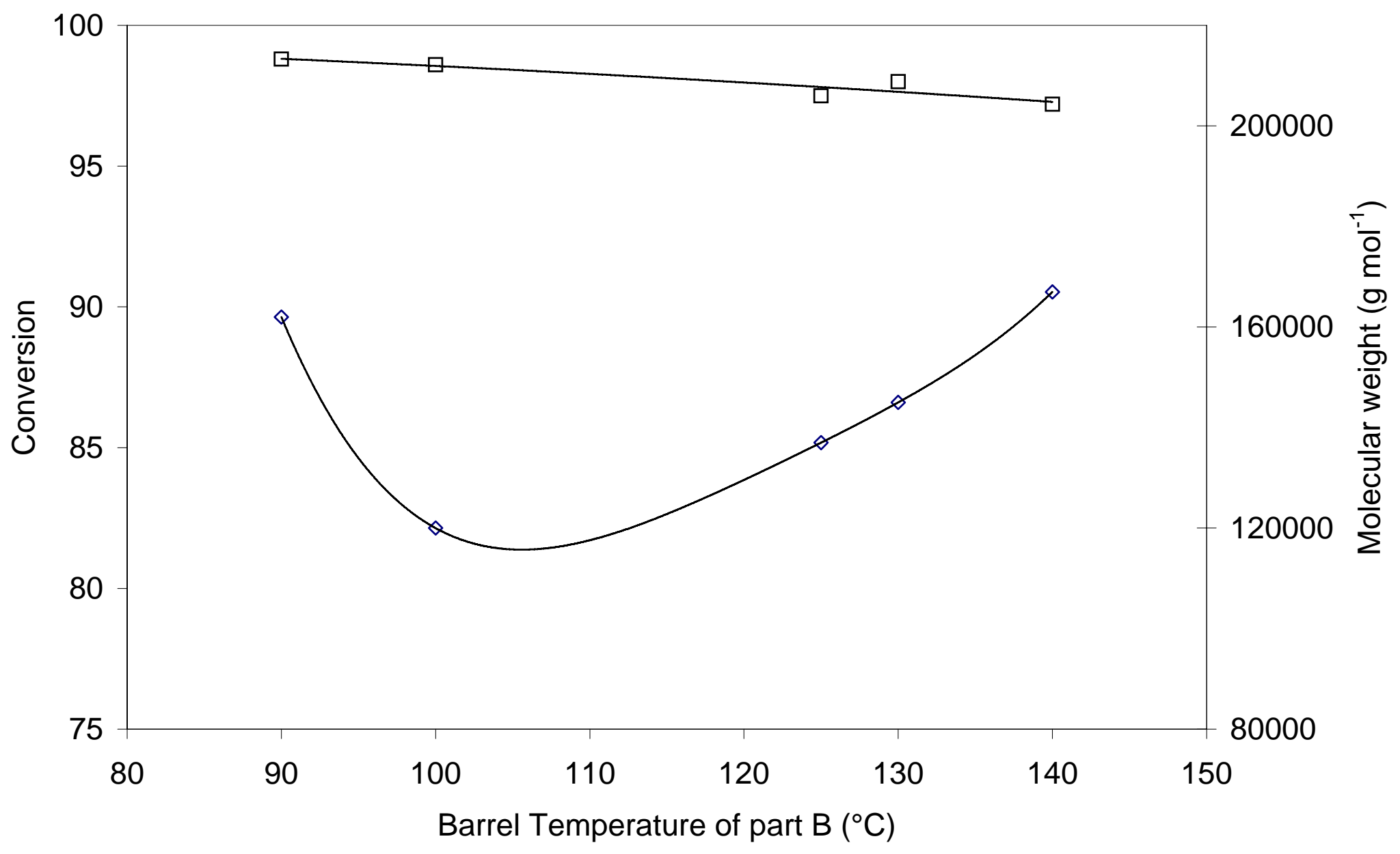

Figure 16: Influence of the temperature of the zone 5 to 9 (part B) on conversion $\square-$ and weight average molar mass $\rightarrow\left(\mathrm{N}: 72 \mathrm{rpm}, \mathrm{Q}: 0.4 \mathrm{~kg} \cdot \mathrm{h}^{-1}\right)$ 


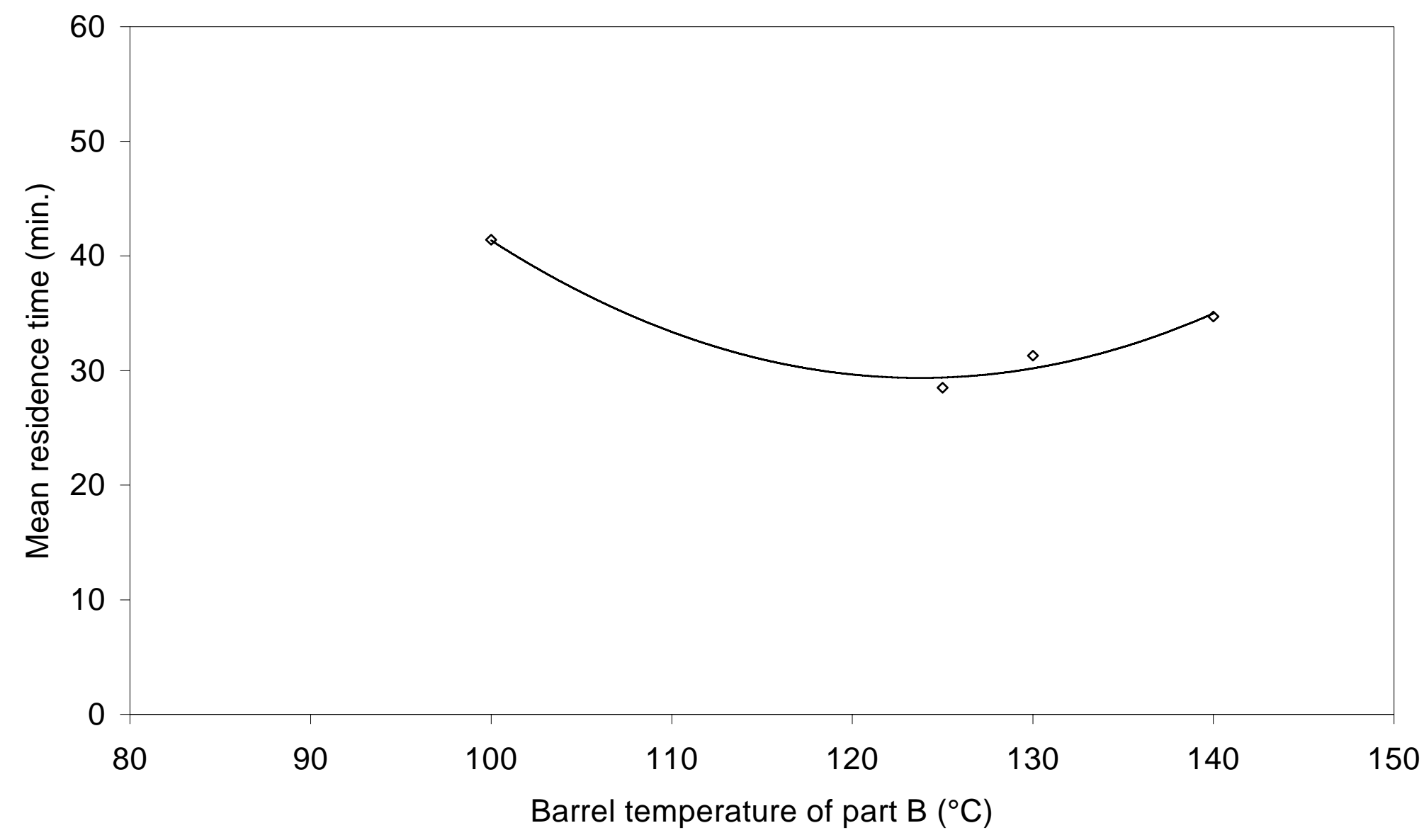

Figure 17: Influence of the temperature of the zone 5 to 9 (part B) on the mean residence time at $\mathrm{N}$ : $72 \mathrm{rpm}, \mathrm{Q}: 0.4 \mathrm{~kg} \cdot \mathrm{h}^{-1}$. 
